\title{
Oligosaccharide and Substrate Binding in the Starch Debranching Enzyme Barley Limit Dextrinase
}

Møller, Marie Sofie; Windahl, Michael Skovbo; Sim, Lyann; Bøjstrup, Marie; Abou Hachem, Maher ; Hindsgaul, Ole; Palcic, Monica; Svensson, Birte; Henriksen, Anette

Published in:

Journal of Molecular Biology

Link to article, DOI:

10.1016/j.jmb.2014.12.019

Publication date:

2015

Document Version

Peer reviewed version

Link back to DTU Orbit

Citation (APA):

Møller, M. S., Windahl, M. S., Sim, L., Bøjstrup, M., Abou Hachem, M., Hindsgaul, O., Palcic, M., Svensson, B., \& Henriksen, A. (2015). Oligosaccharide and Substrate Binding in the Starch Debranching Enzyme Barley Limit

Dextrinase. Journal of Molecular Biology, 427(6, Part B), 1263-1277. https://doi.org/10.1016/j.jmb.2014.12.019

\section{General rights}

Copyright and moral rights for the publications made accessible in the public portal are retained by the authors and/or other copyright owners and it is a condition of accessing publications that users recognise and abide by the legal requirements associated with these rights.

- Users may download and print one copy of any publication from the public portal for the purpose of private study or research.

- You may not further distribute the material or use it for any profit-making activity or commercial gain

- You may freely distribute the URL identifying the publication in the public portal 
Oligosaccharide and substrate binding in the starch debranching enzyme barley limit dextrinase

AUTHORS : Marie S. Møller ${ }^{\mathrm{a}, \mathrm{b}}$, Michael S. Windahl ${ }^{\mathrm{a}, 4} *$, Lyann Sim $^{\mathrm{a}, 5}$, Marie Bøjstrup $^{\mathrm{a}, 6}$, Maher Abou Hachem $^{\mathrm{b}}$, Ole Hindsgaul ${ }^{\mathrm{a}, 2}$, Monica Palcic ${ }^{\mathrm{a}, 3}$, Birte Svensson ${ }^{\mathrm{b}}$, Anette Henriksen ${ }^{\mathrm{a}, 1}$ AUTHOR INFORMATIONS: ${ }^{a}$ Carlsberg Laboratory, Gamle Carlsberg Vej 10, DK-1799 Copenhagen V, Denmark; ${ }^{b}$ Enzyme and Protein Chemistry, Department of Systems Biology, Technical University of Denmark, Søltofts Plads, Building 224, DK-2800 Kgs. Lyngby, Denmark, email: bis@bio.dtu.dk.

Present address: ${ }^{1}$ Novo Nordisk A/S, Novo Nordisk Park, DK-2760 Måløv, Denmark, email: anette.henriksen@gmail.com; ${ }^{2}$ hindsgaulole@gmail.com; ${ }^{3}$ monicapalcic@gmail.com; ${ }^{4}$ Roskilde University, Department of Science, Systems and Models, Universitetsvej 1, Building 18.1, DK-4000 Roskilde, Denmark, email: windahl@ruc.dk; ${ }^{5}$ Department of Chemistry and Biology, Ryerson University, 350 Victoria Street, Toronto, ON, Canada, email: lya.sim@gmail.com; ${ }^{6}$ Pfizer Consumer Healthcare, Sydmarken 5, DK-2860 Søborg, Denmark, email: marie_boejstrup@hotmail.com

CORRESPONDING AUTHOR: Anette Henriksen, Carlsberg Laboratory, Gamle Carlsberg Vej 10, DK-1799 Copenhagen V, Denmark. ${ }^{1}$ Present address: Novo Nordisk A/S, Novo Nordisk Park, DK2760 Måløv, Denmark, email: anette.henriksen@gmail.com, telephone: +45 28144718 and Birte Svensson, Enzyme and Protein Chemistry, Department of Systems Biology, Technical University of Denmark, Søltoft Plads, Building 224, DK-2800 Kgs. Lyngby, Denmark, email: bis@bio.dtu.dk

*These authors contributed equally to the work 


\begin{abstract}
Complete hydrolytic degradation of starch requires hydrolysis of both the $\alpha-1,4-$ and $\alpha$-1,6-glucosidic bonds in amylopectin. Limit dextrinase is the only endogenous barley enzyme capable of hydrolyzing the $\alpha-1,6$-glucosidic bond during seed germination and impaired limit dextrinase activity inevitably reduces the maltose and glucose yields from starch degradation. Crystal structures of barley limit dextrinase and active site mutants with natural substrates, products and substrate analogues were sought to better understand the facets of limit dextrinase-substrate interactions that confine high activity of limit dextrinase to branched malto-oligosaccharides. For the first time, an intact $\alpha$-1,6-glucosidically linked substrate spanning the active site of a limit dextrinase or pullulanase has been trapped and characterized by crystallography. The crystal structure reveals both the branch and main chain binding sites and is used to suggest a mechanism for nucleophilicity enhancement in the active site. The substrate, product and analogue complexes were further used to outline substrate binding subsites, substrate binding restraints and to suggest a mechanism for avoidance of dual $\alpha-1,6-$ and $\alpha-1,4-$ hydrolytic activity likely to be a biological necessity during starch synthesis.
\end{abstract}




\section{Keywords}

Pullulanase, $\alpha$-1,6-glucosidase, substrate specificity, thio-oligosaccharide, transglycosylase

\section{Abbreviations:}

Bis-Tris, 2-bis(2-hydroxyethyl)amino-2-(hydroxymethyl)-1,3-propanediol; CD, cyclodextrin; DTT, dithiothreitol; $\mathrm{GG}^{2} 3 \mathrm{G}^{2} 3,6^{3}$ - $\alpha$-D-glucosyl-maltotriosyl-maltotriose; G2, maltose; G2S- $\beta C D, 6-S-(\alpha-D-$ maltosyl)-6-deoxy-6-thiocyclomaltoheptaose; G2SG $3,6^{3}$ - $\alpha$-D-maltosyl-6-thiomaltotriose; G2SG ${ }^{2} 4$, $6^{3}$ - $\alpha$-D-maltosyl-6-thiomaltotetraose; G3, maltotriose; G3-G $3,6^{2}$ - $\alpha$-D-maltotriosyl-maltotriose; $\mathrm{G}_{3} \mathrm{G}^{2} 4,6^{3}-\alpha$-maltotriosyl-maltotetraose; G4, maltotetraose; GH13, glycoside hydrolase family 13; GH13_13, GH13 subfamily 13; Glc, glucose; HvAMY1, Hordeum vulgare amylase isoform 1; HvLD, Hordeum vulgare limit dextrinase; $H v \mathrm{LD}-\mathrm{M} 440 \mathrm{G}, H \nu \mathrm{LD}$ with position 440 mutated to glycine; $H v \mathrm{LD}-$ E510A, HvLD with position 510 mutated to alanine; KpPUL, Klebsiella pneumoniae (Enterobacter aerogenes) pullulanase; LD, limit dextrinase; MES, 2-( $N$-morpholino)ethanesulfonic acid; PDB, Protein Data Bank; PUL, pullulanase. 


\section{Introduction}

Starch is the major plant storage carbohydrate. It not only provides energy for the plant during growth phases with inadequate or no photosynthesis but it also constitutes an essential calorie and carbon source for human and animal nutrition. It is the essential raw material in many biotechnological industries, e.g. in brewing, bio-refineries and in the production of high-fructose and glucose (Glc) syrups. Cereal grains like maize, rice, wheat, barley and sorghum are the major sources of nutritional and industrial starch. Amylopectin and amylose, which are the two polysaccharide constituents of starch, are tightly packed in semi-crystalline granules in the grains and in the photosynthetic organs. While amylose is an essentially linear 1,4- $\alpha$-glucan chain of 200-1000 Glc units, the linear $\alpha-1,4-$ linked glucosyl chains in amylopectin are connected via $\alpha-1,6$-bonds [1] to form large branched molecules of 2000-200000 Glc units [2]. During e.g. barley seed germination, the carbon and energy stored as starch is mobilized by the concerted action of a pool of different amylolytic enzymes that includes $\alpha$-amylases, $\beta$-amylases, limit dextrinase (LD) and $\alpha$-glucosidases. Among these enzymes, only LD has the capacity to hydrolyze the $\alpha$-1,6-glucosidic linkages of branched maltooligosaccharides produced by the amylases and $\alpha$-glucosidases $[3,4]$. Low LD content therefore has biotechnological consequences during beer brewing where barley malt with a low LD content can be correlated with a limit dextrin rich/high calorie mash and reduced ethanol yield [5-9]. The biological impact of a LD null mutation in maize is an attenuated germination rate and an enhanced phytoglycogen phenotype [10].

Barley limit dextrinase (HvLD, E.C. 3.2.1.142) is a CAZy glycoside hydrolase family 13 (GH13) enzyme [11]. The GH13 enzymes, also known as the $\alpha$-amylase family, are grouped based on sequence

similarities and all members act on $\alpha$-glycosidic bonds. The family is quite diverse with regard to enzyme activities and substrate specificities, though, and it is currently subdivided into 40 subfamilies based on high sequence similarity scores to reflect this diversity [12]. $H v$ LD and $H v L D-l i k e$ debranching enzymes are assigned to GH13 subfamily 13 (GH13_13) together with closely related bacterial pullulanases (PULs). Other closely related bacterial PULs are found in subfamilies GH13_12 and GH13_14. Since the debranching enzymes of all three subfamilies show high activity towards pullulan, a linear polysaccharide composed of $\alpha$-1,6-linked maltotriose (G3) units produced by the yeast-like fungus Aureobasidium pullulans [13], they are often all referred to as pullulanases. However, 
the in-vivo substrates for the $H v$ LD-like plant enzymes from GH13_13 are believed to be limit dextrins; i.e. small branched maltooligosaccharides generated from amylopectin degradation by $\alpha$ - and $\beta$ amylases. $H v \mathrm{LD}$ has the capacity to hydrolyze $\alpha-1,6$-linked branches in amylopectin as well, but the efficiency is low (this study).

The catalytic mechanism of GH13 members follows a general double displacement mechanism that proceeds in two steps and involves the formation and breakdown of a covalent glycosyl-enzyme intermediate via oxocarbenium ion-like transition states [14,15]. The $\alpha-1,6$-glucosidic linkage is cleaved with retention of the anomeric configuration [4]. Catalysis involves an aspartic acid catalytic nucleophile, which forms the covalent adduct and a glutamic acid general acid/base catalyst. In addition, a third carboxylic acid residue thought to be a transition state stabilizer is required for catalytic activity $[16,17]$.

Three crystal structures of $H v \mathrm{LD}$ have been published; $H v \mathrm{LD}$ (Protein Data Bank (PDB) entry 4AIO [18]) and $H v \mathrm{LD}$ in complex with its competitive inhibitors $\alpha$ - or $\beta$-cyclodextrin (CD) (PDB entries $2 \mathrm{Y} 4 \mathrm{~S}$ and $2 \mathrm{Y} 5 \mathrm{E}$ [19]). The $H v \mathrm{LD}$ structure is composed of four domains; the N-terminal domain (residues 2-124 resembling carbohydrate binding module 21 [18]), a carbohydrate binding module 48 (residues 125-230), a catalytic $(\beta / \alpha)_{8}$ domain (residues 231-774) containing the two catalytic residues (Asp473, nucleophile; Glu510, general acid/base) and the transition state stabilizer (Asp642) and a Cterminal domain (residues 775-885) (Fig. 1). In addition to HvLD, two other GH13_13 enzymes have been structurally characterized, the PUL from Kleibsiella pneumoniae (KpPUL) as free enzyme and in complex with Glc, maltose (G2), G3 or maltotetraose (G4), respectively [20], and a PUL from the Klebsiella oxytoca strain without carbohydrate in the active site (PDB entry 2YOC). The KpPUL has an extra N-terminal carbohydrate binding module compared to its plant counterparts. Additionally two structures of Streptococci PULs from GH13_12 [21,22] and three structures of Bacilli PULs from GH13_14 are known [23-25]. None of the debranching enzyme structures published to date have been substrate complexes, i.e. containing linear $\alpha$-1,6-oligosaccharides, small branched limit dextrins or mixed 1,4-/1,6-linked substrates representing fragments of the Glc polymers amylopectin, glycogen or pullulan. Therefore, the exact stereochemistry of the active site for engagement in $\alpha-1,6$-bond hydrolysis of a branched substrate is not known. The nomenclature for branched substrate subsites in glycosyl hydrolases is defined by Davies et al. and Mikami et al. [20,26]. According to this 
nomenclature each subsite interacts with one glycosyl unit. The carbohydrate main chain is embedded in subsites -1 ', 0 ', $+1,+2,+3$ etc., while the branch units are accommodated in the $-3,-2,-1$ subsites. The scissile $\alpha-1,6$-bond of the branched substrate is placed between subsites -1 and +1 (Fig. 2).

Despite the extensive analyses of the GH13 family, there is still a lack of understanding of the key determinants for $\alpha-1,4$ - versus $\alpha$-1,6-glycoside hydrolase activity and the background for the variations in catalytic efficiency on polymeric substrates displayed by the individual debranching enzymes from GH13_12-14 and of the isoamylases from GH13_11. Here we have used three crystallographic approaches to thoroughly map main chain and branch $H v \mathrm{LD}$ substrate binding subsites and to gain insight into the structural features governing 1,6-versus 1,4-hydrolytic activity: i) two structures were solved of catalytically inactive $H \nu \mathrm{LD}$ in complex with the natural substrates $6^{2}$ - $\alpha$-D-maltotriosylmaltotriose $\left(\mathrm{G} 3 \mathrm{G}^{1} 3\right.$; an amylopectin fragment) and with $6^{3}$ - $\alpha$-D-glucosyl-maltotriosyl-maltotriose ( $\mathrm{GG}^{2} 3 \mathrm{G}^{2} 3$; a pullulan fragment), ii) two structures of $H v \mathrm{LD}$ in complex with its products G3 and G4, i.e. linear malto-oligosaccharides were solved, and iii) two structures of $H v L D$ in complex with the substrate analogues $S$-( $\alpha$-D-maltosyl)-6-thio- $\beta$-cyclodextrin $\quad(\mathrm{G} 2 \mathrm{~S}-\beta \mathrm{CD}) \quad$ or $\quad 6^{3}$ - $\alpha$-D-maltosyl-6thiomaltotetraose $\left(\mathrm{G}_{2} \mathrm{SG}^{2} 4\right)$ (Table 1). Furthermore, a structure guided $H v \mathrm{LD}$ variant, $H v \mathrm{LD}-\mathrm{M} 440 \mathrm{G}$, was constructed to clarify the role of this residue and the potential existence of a -4 branch subsite that was not unambiguously characterized by the $H v \mathrm{LD}$-carbohydrate crystal structures.

An intact $\alpha$-1,6-glucosidically linked substrate spanned the active site of the $\mathrm{G}^{1} 3 \mathrm{G}^{1} 3$ and $\mathrm{GG}^{2} 3 \mathrm{G}^{2} 3$ complexes and overall, the compiled structures outlined substrate binding subsites, substrate binding restraints and suggested mechanisms for nucleophilicity enhancement in the LD active site and for avoidance of dual $\alpha-1,6-$ and $\alpha-1,4$-hydrolytic activity.

\section{Results}

\section{Enzyme activity}

The specific activity of wild type $H v \mathrm{LD}$ was determined to $2.2 \mathrm{U} / \mathrm{mg}$ using the Limit Dextrizyme assay from Megazyme. The catalytically inactive $H v$ LD-E510A was shown to have a residual activity of $0.0004 \%$ in the reducing sugar assay [27] with the pullulan substrate.

\section{Overall structure}

The six $H v \mathrm{LD}$ crystal structures were solved to resolutions ranging from $1.45 \AA$ to $1.75 \AA$ (Table 1 ). All had overall structures identical to that of the previously published HvLD structures (PDB entry 
4AIO [18], 2Y5E and 2Y4S [19]) (Fig. 1a). As in the case of the previously solved structures of $H v L D$ in complex with $\alpha$ - and $\beta-\mathrm{CD}$, the $\mathrm{N}$-terminal region (residues 1-5) and three loop regions (residues 24-27, 42-46 and 102-108) were disordered, albeit to varying extent. For the most part, all $H v L D$ structures were crystallized in the same space group, although the length of the $c$-axis was increased 2fold in the G2S $\beta C D$ co-crystallized complex and thus the asymmetric unit of the $H v \operatorname{LD}$ G $2 \mathrm{~S} \beta C D$ complex contained two $H v$ LD molecules related by non-crystallographic symmetry. This crystal form was observed in a very small population of all the LD crystallization experiments and was not a result from the binding of the G2S $\beta C D$. It was generated by a $5.3 \AA$ rigid-body translocation of the second LD molecule in the asymmetric unit of the $H v \mathrm{LD}$ G2S $\beta C D$ complex, and it is possible that the crystal packing heterogeneity was a result of incomplete saturation of the third G4 binding site observed in the $H v \mathrm{LD}$ maltotetraose crystal structure (see the $H v \mathrm{LD}$ maltotetraose binding section).

\section{Active site of the HvLD-E510A G3G 3 complex}

The inactive variant $H v \mathrm{LD}-\mathrm{E} 510 \mathrm{~A}$ was soaked with $\mathrm{G}_{3} \mathrm{G}^{1} 3$, which is an $\alpha$-1,6-branched limit dextrin derived from amylopectin degradation, i.e. a plausible in-planta substrate. Significant electron density (larger than $1.0 \sigma$ in a sigmaA weighted 2Fo-Fc map) was observed for all carbon atoms in the Glc units, which occupied subsites 0 ', $+1,+2$ and $-1,-2,-3$ (Supplemental Fig. S1a). The Glc unit in subsite 0' was hydrogen bonded to Arg697, Asp698, and Lys727 and stacked against the Glc unit at subsite -2 (Fig. 1b, Fig. 3b and Supplemental Video). Tyr700 stacked onto the Glc unit in subsite -2 . Tyr357 stacked with the Glc unit in subsite -1 , while hydrogen bonds were found between the catalytic nucleophile, Asp473 and the hydroxyl groups of C2 and C6 and between the transition state stabilizing Asp642 and the hydroxyl groups of C2 and C3 in this subsite. Most remarkably, Asp642 was not in the same rotamer as observed in the uncomplexed structure and in the structures with the competitive inhibitors $\alpha$ - or $\beta$-CD bound (Fig. 1c). The $\alpha$-1,6-linkage was positioned in the active site adjacent to the catalytic residues Asp473, Ala510 (Glu510 general acid/base in wild type HvLD) and Asp642. Two water molecules were found in the $H v \mathrm{LD}-\mathrm{E} 510 \mathrm{~A}$ inactive variant in positions corresponding to Glu510 OE1 and OE2 in the native uncomplexed enzyme (PDB entry 4AIO) (Fig. 1c). Trp512 stacked onto the Glc unit in subsite +2 . A list of amino acid residues with hydrogen bonds or van der Waals interactions to the $\mathrm{G} 3 \mathrm{G}^{1} 3$ molecule can be found in the supplemental material (See supplemental Table S1 for a list and supplemental Fig. S1b for a structural formula representation of the $H v L D-E 510 A-G 3 G^{1} 3$ active 
site. The puckering parameters observed for the $\alpha$-D-glucose unit in the -1 subsite are listed in supplemental Table S2).

\section{Active site of the $H v L D-E 510 A$ variant $G^{2} 3 G^{2} 3$ complex}

The $\mathrm{GG}^{2} 3 \mathrm{G}^{2} 3$ is a substrate for $H v \mathrm{LD}$ but it also represents a fragment of pullulan and although it contains both $\alpha-1,4$ and $\alpha-1,6$-glucosidic linkages it is not a branched substrate. A crystal structure of the complex was obtained with the inactive $H v L D-E 510 \mathrm{~A}$ variant. There was significant $2 \mathrm{mFo}-\mathrm{DFc}$ electron density for all seven Glc moieties, but the first Glc901 unit at subsite -3 had a larger average B-factor than the rest of the molecule $\left(B_{\text {average }} G^{\prime \prime} 3-G^{\prime \prime} 3=17.2 \AA^{2}\right.$, B average first Glc901 unit $=59.3 \AA^{2}$ ) and only a few intermolecular contacts. The two G3 moieties occupied subsites +1 to +3 and -1 to -3 as illustrated in Fig. 3c and supplemental video, however, the Glc907 unit in the potential +3 subsite only had intermolecular interaction with Phe553 (See supplemental Table S1 for a list and supplemental Fig. S2 for a structural formula representation of the $H v \mathrm{LD}-\mathrm{E} 510 \mathrm{~A}-\mathrm{GG}^{2} 3 \mathrm{G}^{2} 3$ active site). The $\alpha-1,6$-linkage was positioned in the active site adjacent to the catalytic site residues Asp473, Ala510 and Asp642 similar to the positioning of the $\alpha$-1,6-linkage in the $\mathrm{G}^{3} \mathrm{G}^{1} 3$ complex (See supplemental Fig. S1). The two water molecules found in positions corresponding to Glu510 OE1 and OE2 in the wild type enzyme had well-defined electron densities in this complex as well.

\section{$H v L D$ maltotetraose binding}

Two wild type $H v L D$ structures were obtained in complex with G4; one had been co-crystallized with a low concentration of a mixture of $25 \mathrm{mM} \mathrm{G} 3$ and $25 \mathrm{mM} \mathrm{G} 4$ and one had been soaked with $300 \mathrm{mM}$ G4 (Table 1). The low concentration G3/G4 co-crystallization structure revealed binding of oligosaccharide only in the main chain binding subsites. Glc units could be modeled into the main chain subsites 0 ', +1 and +2 with full occupancy, while Glc units with a lower occupancy could be modeled in the main chain subsites +3 and -1 '(Fig. $3 \mathrm{~d}$ and supplemental video). No apparent density that resembled Glc could be located at the branch binding subsites $-1,-2$ and -3 . Consequently, two partly superposed G4 molecules each with occupancy of 0.5 were built in the electron density. One G4 chain occupied subsites $-1^{\prime}, 0$ ', +1 and +2 , and the other chain occupied the subsites 0 ', $+1,+2$, and +3 (Fig. 3d and supplemental Fig. S3a).

$H v \mathrm{LD}$ crystals soaked with a high concentration of G4 (300 mM), however, had both main chain and branch-binding sites occupied with G4 molecules and the two G4 molecules did not superpose but could be modeled as a G4 in the $0,,+1,+2$ and +3 subsites and as G3 in the $-4,-3$, and -2 subsites, 
respectively (Fig. 3e See supplemental Fig. S3b). The electron densities at subsites +3 and -4 were not as well-defined as in subsites 0 ' to +2 and -2 to -3 , respectively and these most peripheral Glc units had only few intermolecular interactions (See supplemental Fig. S3b for structural formula representations of the $H v \mathrm{LD}-\mathrm{G} 4$ active sites). Interestingly, there was no electron density in subsite -1 ' and there was an indication of low subsite -1 occupancy at high G4 concentration by a mixture of continuous and broken $2 \mathrm{Fo}-\mathrm{Fc}$ electron density.

A third G4 binding site was observed at the surface of LD at the interface between three $H v L D$ monomers in the crystal soaked with 300 mM G4 (See supplemental Fig. 4). Here, the G4 molecule interacted with residues K247, L301, S297, D298, R294, R391, R582 via hydrogen bonding interactions but the presence of the G4 molecule at the interface between three $H v$ LD monomers makes an interpretation of this site as a genuine surface binding site questionable and is likely an artifact of the high concentration of G4 used.

Other than the presence of additional sugars in the $300 \mathrm{mM} \mathrm{G} 4$ soak, there were no significant differences in the overall LD structure and active site architecture between the low and high concentration soaks. This observation suggests the presence of high and low affinity ligand binding sites in the active site, of which the latter is revealed upon soaking with higher concentrations of ligand.

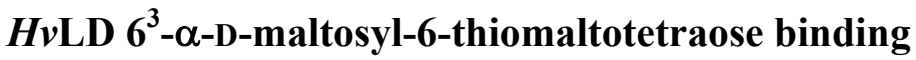

$H v \mathrm{LD}$ crystals were soaked with the mixture of $\mathrm{G}_{2} \mathrm{SG}^{2} 4$ and $6^{3}-\alpha$-D-maltosyl-6-thiomaltotriose $\left(\mathrm{G}_{2} \mathrm{SG}^{2} 3\right)$, the products from Novamyl treatment of G2S- $\beta C D$. The structure revealed the presence of two oligosaccharide structures; one, a G4, in the main chain site and one, a G2SG ${ }^{2} 4$, in the branchbinding site, respectively (Fig. $3 \mathrm{f}$ and supplemental video). Four Glc units were built into the electron density at subsites $0,,+1,+2$ and +3 . Extra electron density attached to the $\mathrm{O} 6$ atom at subsite +1 indicated the location of a thiol-1,6-linkage, but there was no significant electron density for a thiollinkage in an anomalous Fourier map, and there was neither significant electron density for a maltose molecule nor a Glc unit extending from the C6 atom of the Glc at the +1 subsite. In the branch binding site, there was substantial and coherent electron density at the $-1,-2,-3$ positions and weaker but continuous density for a branch at the $\mathrm{C} 6$ atom of the Glc at subsite -3 corresponding to the structure of the $\mathrm{G}_{2} \mathrm{SG}^{2} 4$ molecule (Fig. 3f). Anomalous maps supported the presence of sulfur at the thio-linkage position in subsite -3 , but $1.0 \sigma$ sigmaA weighted negative Fo-Fc electron density surrounded the 
sulfur linkage, perhaps due to radiation damage (See supplemental Fig. S5 for a structural formula representation of the $H \nu \mathrm{LD}-\mathrm{G}_{2} \mathrm{SG}^{2} 4$ active site).

\section{$H v$ LD 6-S-( $\alpha$-D-maltosyl)-6-deoxy-6-thiocyclomaltoheptaose binding}

$\alpha-(1,6)-O$-maltosyl- $\beta-\mathrm{CD}$ is a substrate for $H v \mathrm{LD}$, while the corresponding sulfur linked G2S $\beta \mathrm{CD}$ is a potent inhibitor of $H v \mathrm{LD}$ [28]. The cyclic part of G2S $\beta C D$ was bound in the active site of $H v \mathrm{LD}$ analogous to the binding of $\beta-\mathrm{CD}$ in the $H \nu \mathrm{LD}-\beta-\mathrm{CD}$ structure (PDB code $2 \mathrm{Y} 4 \mathrm{~S}$ ) [19]. The side chain of Phe553 was immersed into the central cavity of the $\beta-C D$ moiety and Glc units occupied the main chain subsites $0^{\prime},+1,+2$ and +3 . Trp512 was stacking against the subsite +2 Glc unit of G2S $\beta C D$ as in the $H v \mathrm{LD}-\beta-\mathrm{CD}$ structure. However, the position of the solvent exposed part of the G2S $\beta \mathrm{CD}$ was shifted $1.8 \AA$ compared to $\beta-\mathrm{CD}$ in the $H v \mathrm{LD}-\beta-\mathrm{CD}$ structure. In the $H v \mathrm{LD}-\beta-\mathrm{CD}$ structure, there is no clear electron density for the side chain of Phe620, while in the $H v \mathrm{LD}-\mathrm{G} 2 \mathrm{~S} \beta \mathrm{CD}$ structure, the loop containing Phe620 was moved towards the CD ring and the electron density of Phe620 was well

defined and stacked against the subsite +3 Glc unit. The C $\alpha$ of Phe 620 was moved 4.6 A. Surprisingly, the maltosyl moiety of G2S $\beta C D$ did not occupy the branch-binding site but branched from subsite +2 and interacted with $H \nu$ LD by stacking against Ser437, Phe514 and Ala515 (Fig. 3g and supplemental video) (See supplemental Fig. S6 for a structural formula representation of the $H \nu$ LD-G2S $\beta C D$ active site).

\section{Effect of Met440 substitution}

Met440 is situated in a potential subsite -4 and has been suggested to be implicated in limiting the activity of $H v \mathrm{LD}$ on large branched substrates [19]. Met440 was substituted with glycine, the residue most often found in the similar position in PULs (See supplemental Fig. S7 for a LD/PUL sequence alignment), and the catalytic parameters for $H v \mathrm{LD}$ hydrolysis of pullulan and amylopectin were determined. The Met440Gly substitution had no effect on pullulan hydrolysis, while a slightly lower $K_{\mathrm{m}}$, a four-fold decrease in $k_{c a t}$ and a 2.6 -fold decrease in $k_{\text {cat }} / K_{\mathrm{m}}$ were observed for amylopectin hydrolysis (Table 2).

\section{Discussion}

Substrate selectivity - main chain binding

Based on an analysis of key subsites in the GH13 family, Kumar [29] suggested that GH13 enzymes recognize their substrates based on the shape of subsites rather than on specific interactions within the 
binding site. The enzyme:substrate and enzyme:ligand crystal structures solved in the present study made it possible to identify six core Glc-binding subsites in the catalytic site and its vicinity in agreement with previous observations from the KpPUL-G4 ligand complex [20]; three main chain subsites $\left(0^{\prime},+1\right.$, and +2$)$ and three branch subsites $(-1,-2$, and -3$)$. However, the structure of $H v \mathrm{LD}$ soaked with G4 revealed that the length of the main chain can be at least five Glc units long and span the three core main chain subsites and two peripheral subsites $(-1$ ' and +3$)$; one at each end of the main chain binding cleft. Apparently, two is the optimal number of Glc units, which can be accommodated at the non-reducing side of the main chain after the $\alpha-1,6$-glucosidic linkage, i.e. in subsite -1 ' and 0 '. The result is in perfect agreement with kinetic data for $H v \mathrm{LD}$ purified from malt that shows $K_{\mathrm{m}}$ values in the $0.5-0.8 \mathrm{mM}$ range for small limit dextrins (6-7 Glc units), with $k_{\mathrm{cat}}$ varying from $85 \mathrm{~s}^{-1}$, when there were three main chain Glc units on the non-reducing side of the $\alpha-1,6$-linkage, to approximately $215 \mathrm{~s}^{-1}$ when there are one or two Glc units on the non-reducing side $[28,30]$.

At the reducing end of the main chain, subsites +1 and +2 stand out as being critically important for substrate binding. The $\mathrm{CD}$ inhibitors bind to these subsites with high affinity ( $K_{\mathrm{d}}$ for $\beta$-CD is $0.7 \mu \mathrm{M}$ ) [19], and Phe553 and Trp512 sandwich the main chain of branched substrates at subsite +2 positioning the $\alpha-1,6$-glucosidic linkage for hydrolysis. Trp512 is at the same side of the substrate plane as the catalytic residues and is part of the conserved GH13 region III indicating that this residue is a pivot for substrate binding to GH13 in general as previously suggested [16]. Phe553, on the other hand, is not generally conserved in GH13 enzymes, but it is conserved in LDs and PULs (Supplemental Fig. S7).

Four of the crystal structures have a Glc unit bound in subsite +3 . It is relevant to assign a subsite +3 in relation to the binding of pullulan, because this subsite accommodates the G3 moiety at the reducing end of the $\alpha-1,6$-linkage. The $H \nu \mathrm{LD}-\mathrm{E} 510 \mathrm{~A}$ structure with $\mathrm{GG}^{2} 3 \mathrm{G}^{2} 3$ bound illustrates the binding of pullulan. The loop containing Phe620 and Asp621, which interacts with the Glc unit at the +3 positions, seems to be quite dynamic, though, and in the previously published structure of $H v \mathrm{LD}$ in complex with $\beta$-CD [19] there was no electron density for the side chain of Phe620, and Asp621 did not make hydrogen bonds with the $\beta-C D$. In the present structure of $H \nu \mathrm{LD}-\mathrm{G} 2 \mathrm{~S} \beta \mathrm{CD}$, Phe620 is stacking against a Glc of the CD ring at subsite +3 , and again, Asp621 does not contribute to the interaction. There are no indications that crystal packing influences the $H \nu \mathrm{LD}-\mathrm{G} 2 \mathrm{~S} \beta \mathrm{CD}$ interactions. Phe620 is a conserved residue (Phe, Tyr or His) in LD/PUL from GH13_13 but is not conserved in the 
GH13_12 and GH13_14 subfamilies. A tyrosine is seen in the corresponding position in the KpPUL structures (GH13_13) [20], but the entire loop carrying the Phe620 and Asp621 for subsite +3 interactions is absent in the PULs from GH13_12 [21,22] and GH13_14 [23-25]. It is likely that this dynamic Phe620-Asp621 loop is important for $H v L D$ activity on different length limit dextrins during amylopectin conversion. The loop could impede the effective binding of substrates with a main chain length of more than four Glc units. This is in agreement with hydrolysis kinetics results on different well-defined limit dextrins which showed $6^{3}$ - $\alpha$-maltotriosyl-maltotetraose $\left(\mathrm{G}_{3} \mathrm{G}^{2} 4\right)$ is the optimal substrate for $H v L D$ [28].

Likewise, it seems that the surface binding of the maltosyl-chain of the G2S $\beta C D$ to Ser437, Phe514 and Ala515 (Fig. 3) has a function in positioning longer limit dextrins in the active site or limit dextrins with branch points on two neighboring main chain Glc units. Furthermore, the structure of $H v L D-$ G2S $\beta C D$, with the thio- $\alpha-1,6$ branch at the +2 subsite, indicates that the presence of $\alpha-1,6$ branches on neighboring Glc units would not make substrate binding and debranching futile. KpPUL has even more space for a neighboring substrate branch in this position since a serine is found in the position corresponding to $H v \mathrm{LD}$ Phe514 [20], but serine would not be able to contribute to branch binding with aromatic residue stacking interactions. The interactions from the maltosyl-chain of the G2S $\beta C D$ to $H \nu \mathrm{LD}$ is probably the explanation for the increased inhibitory effect of $\mathrm{G} 2 \mathrm{~S} \beta \mathrm{CD}\left(K_{\mathrm{i}}\right.$ is $\left.0.46 \mu \mathrm{M}\right)$ compared to $\beta-\mathrm{CD}\left(K_{\mathrm{i}}\right.$ is $\left.0.7 \mu \mathrm{M}\right)$ [31].

\section{Substrate selectivity - branch binding}

From structural comparisons between $H v$ LD and $K p$ PUL we previously suggested that Met440 near subsite -3 could cause steric hindrances for binding of longer branches by obstructing the formation of a -4 subsite and thereby explain the lower activity of $H v \mathrm{LD}$ on larger branched substrates as compared with bacterial PULs from GH13_12 or GH13_14, which commonly have a glycine at the corresponding position [19] (Supplemental Fig. S7). However, the present crystal structures of $H v L D$ with the longer branch substrates/ligands $\mathrm{G}_{2} \mathrm{SG}^{2} 4$ and $\mathrm{GG}^{2} 3 \mathrm{G}^{2} 3$ bound show that Met440 is flexible and the mutational analysis showed a small (2.6-fold) reduction in HvLD-M440G catalytic efficiency $\left(k_{\text {cat }} / K_{\mathrm{m}}\right)$ using amylopectin as a substrate with classical Michaelis-Menten kinetics (Table 2). The mutation resulted in a modest decrease in $K_{\mathrm{m}}$. The differences in substrate specificity between the different debranching enzymes from GH13 with regard to very large branched substrates like 
amylopectin therefore seems to be have more causes than deletion or addition of interactions at this specific subsite. The limited effect of the Met440G mutation indicates substrate specificity of this class of enzymes to be the result of the combined effect of interactions and shape complementarity over a larger section of the polymeric substrate in accordance with the suggestion by Kumar [29]. Furthermore some PULs, like the structurally characterized GH13_12 pullulanase from Streptococcus pneumoniae, have more carbohydrate binding modules than $H v \mathrm{LD}$. These modules have been shown to be especially important for activity on polymeric substrates [22].

The aim of soaking $H v \mathrm{LD}$ crystals with thioglycosides such as $\mathrm{G} 2 \mathrm{SG}^{2} 4$ and $\mathrm{G} 2 \mathrm{~S} \beta C D$ was to get the thio- $\alpha-1,6$ bond to span the active site to clarify the reaction preference of $\alpha-1,6-$ versus $\alpha-1,4-$ glucosidases. It was not possible to achieve this with $\mathrm{G} 2 \mathrm{SG}^{2} 4$ nor with the G2S $\beta C D$ compound, though. The present $H v \mathrm{LD}-\mathrm{G} 2 \mathrm{SG}^{2} 4$ and $H v \mathrm{LD}-\mathrm{G} 2 \mathrm{~S} \beta C D$ structures revealed that the thio-bond of these compounds does not fit and span the central active site of $H \nu \mathrm{LD}$ but rather interacts with other surface sites as described above for the G2S $\beta C D$ interactions with the dynamic Phe620-Asp621 loop. The $\alpha$-1,6-thio branch of $H v \mathrm{LD}-\mathrm{G} 2 \mathrm{SG}^{2} 4$ interacted with Met440 and Asp406 and showed that additional $\alpha-1,6$-branches can be accepted on the Glc unit in subsite -3 (Fig. 3f and supplemental Fig. S5).

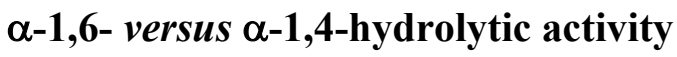

Unlike the preferred binding of ligands in the subsites at the reducing side of the $\alpha-1,6$-linkage seen in this study, the $\alpha-1,4$-hydrolytic barley amylase isoform 1 (HvAMY1) preferentially binds ligands in the subsites at the non-reducing side of the cleaved bond [32]. A superposition of the HvAMY1 active site and the $H v \mathrm{LD}-\mathrm{G} 3 \mathrm{G}^{1} 3$ active site shows that $H v \mathrm{LD}$ branch binding sites -1 and -2 closely resemble the -1 and -2 subsites in HvAMY1 (Fig. 4a). It is noteworthy that the catalytic machinery in terms of the $H \nu \mathrm{LD}$ nucleophile (Asp473), general acid/base (Glu510), and the transition state stabilizer (Asp642) are identically positioned for catalysis in $H v A M Y 1$ and $H v L D$. Also the position of Asp642 in subsite 1 , whose equivalent is essential for activity in GH13 $\alpha$-amylases is conserved [33].

The oxocarbenium-like transition states of $\alpha$-1,6-glycoside hydrolases are believed to be stabilized by interactions from several conserved amino acids in the active site, especially two histidine residues: 
KpPUL His607 and His833, which correspond to HvLD His404 and His641, respectively [34]. The orientation of a His amino acid residue in the electron density is to some extent ambiguous and will depend on the presence of adjacent hydrogen bonding partners. His607 NE2 in KpPUL is proposed to hydrogen bond (3.2 $\AA$ ) to the $\mathrm{O} 6$ of the Glc unit in subsite -1 in the structure of KpPUL-G4 [20] and His607 mutagenesis resulted in loss of activity [34]. HvLD His404 was previously suggested to be important in substrate binding as the residue interacted with a glycerol molecule in the active site [19]. In the $H v \mathrm{LD}$ structures presented here, the hydrogen bonding pattern of His404 and hence its orientation was interpreted differently (Fig. 4b). All HvLD structures show hydrogen bond distances (2.6-2.7 $\AA$ ) between Asn403 OD1 and His404 ND1 (correspondingly, the Asn606 OD1 to His607 CD2 distance is $2.7 \AA$ in $K p$ PUL-G4) and have a water molecule within hydrogen bonding distance of His404 NE2 (2.7-2.8 $\AA$ ) (the corresponding water to His607 CE1 distance is $3.0 \AA$ in $K p \mathrm{PUL}-\mathrm{G} 4)$. The smallest His404 to O6 distance, on the other hand, varied from $3.2 \AA$ in the $H v \mathrm{LD}-\mathrm{E} 510 \mathrm{~A}-\mathrm{G} 3 \mathrm{G}^{1} 3$ structure to $4.1 \AA$ in the $H \nu \mathrm{LD}-\mathrm{E} 510 \mathrm{~A}-\mathrm{GG}^{2} 3 \mathrm{G}^{2} 3$ structure. Consequently, His404 is likely to influence hydrolysis via the hydrogen bond to Asn403 OD1, which position Asn403 ND2 for hydrogen bond donation to Asp473 O and OD2 and increase the acidity (lower pKa) of the nucleophile and ensure a negative charge on the residue for nucleophile attack. Fixing Asp473 by hydrogen bond donation primes it for attack on the $\mathrm{C} 1$ of the Glc in subsite -1. A similar arrangement is not found in the $\alpha-1,4-$ hydrolytic barley amylases. Here, the amino acid residues corresponding to Asn403 (Asn92 in HvAMY1 [35] and Asn91 in HvAMY2 [36]) are part of a $\mathrm{Ca}^{2+}$ binding site, which could also affect the acidity of the nucleophile.

Significant differences were observed at subsite -1 when the structures of $H v$ LD-E510A-G3G 3 and $H \nu \mathrm{LD}-\mathrm{E} 510 \mathrm{~A}-\mathrm{GG}^{2} 3 \mathrm{G}^{2} 3$ were superimposed (Fig. 4c). The Glc unit in subsite -1 in the $\mathrm{GG}^{2} 3 \mathrm{G}^{2} 3$ structure was in a low energy chair conformation, whereas the Glc conformation in subsite -1 in the G3G 3 structure was a twisted chair. C6-OH of $\mathrm{G}^{1} \mathrm{G}^{1} 3$ was hydrogen bonded to OD2 of Asp473, whereas a water molecule was bridging the C6-OH and OD2 of Asp473 in $H v L D-E 510 A-G^{2} 3 G^{2} 3$. The hydrogen bonding between $\mathrm{G}_{3} \mathrm{G}^{1} 3 \mathrm{C} 6-\mathrm{OH}$ and Asp473 could compensate for the energetically unfavorable twist of the Glc ring out of its preferred chair conformation. That the C6-OH in $H v L D-$ E510A-GG $3 \mathrm{G}^{2} 3$ was further away from OD2 of Asp473 could possibly be due to lack of steric constraints from the Glc unit at subsite 0 ' in the $\mathrm{G}^{\prime} \mathrm{G}^{1} 3$ structure, but it could also be a result of the 
E510A mutation, although this mutation was present in both structures. As $\alpha-1,6$-glucosidic bonds are inherently more flexible than $\alpha-1,4$ bonds, owing to additional torsion angles and fewer intramolecular hydrogen bonds between adjacent Glc rings, the inclusion of a Glc unit at subsite 0' could, as seen in the $\mathrm{G}_{3} \mathrm{G}^{1} 3$ structure, help rigidifying the substrate by addition of stacking interaction between the 0' position Glc and the Glc unit in subsite -2 and thus help orient the substrate properly in the active site. Based on kinetic studies by Manners and Yellowlees, $\mathrm{G} 3 \mathrm{G}^{2} 4$ is a better (twice as good) substrate for $H \nu \mathrm{LD}$ than $6^{3}$ - $\alpha$-maltotriosyl-maltotriose [37]. This is also the case for other LD's (sorghum and pea) $[38,39]$. These differences in activity depending on the position of the $\alpha-1,6$-branch indicate a preference for a Glc unit on both sides of the branch, which could reflect an effect of Glc stacking on the substrate binding thermodynamics. Glc stacking between subsites 0 ' and -2 is not a prerequisite for rapid catalysis, though. Pullulan is one of the best substrates for $H v L D$ and PULs in general [40] and the subsite stacking is therefore more likely to be a way to restrict the space needed and the entrophy loss by substrate binding than it is likely to be part of a transition state stabilization mechanism.

Structural comparison of HvLD with the GH13_12 [21,22], GH13_13 [20] and GH13_14 [24] PULs suggests that $H v L D$ Phe553 (Supplemental Fig. S7) and the equivalent tyrosine or phenylalanine in PULs serves the same function. A structure based multiple sequence alignment does not bring the amino acid residues equivalent to Phe553 in perfect alignment (Supplemental Fig. S7) but a superposition of the structures from GH13_12-14 showed that the Phe553 equivalent residues were occupying the same 3D space (Supplemental Fig. S8) and appeared to adopt different conformations to optimize substrate interactions (Fig. 5). In the $H v \mathrm{LD}-\mathrm{G} 2 \mathrm{SG}^{2} 4, H v \mathrm{LD}-\mathrm{G} 4-300 \mathrm{mM}, H v \mathrm{LD}-\mathrm{G} 4-25 \mathrm{mM}$, $H v \mathrm{LD}-\mathrm{E} 510 \mathrm{~A}-\mathrm{G} 3 \mathrm{G}^{1} 3$ structures, the conformation of Phe553 is similar and closer to the active site acid-base catalyst as compared to the active site distances in the rest of the structures, where the Phe553 to active site distance is increased following: $H \nu \mathrm{LD}-\mathrm{E} 510 \mathrm{~A}-\mathrm{GG}^{2} 3 \mathrm{G}^{2} 3<H \nu \mathrm{LD}-\mathrm{G} 2 \mathrm{~S} \beta \mathrm{CD}<$ free $H v \mathrm{LD}$ wild type. Together with a tryptophan residue (HvLD Trp512), Phe553 sandwiches the main chain oligosaccharide in subsites +1 and +2 . The binding of the substrate main chain to the +2 and +1 subsites appears to favor binding of additional main chain $\alpha$-1,4-linked moieties of the non-reducing end into the subsites 0' and -1' on the Phe553 loop (this study and Mikami et al. [20]). No active site $\alpha-1,4-$ link spans the main chain binding subsites +1 and +2 into the -1 and -2 subsites in any of the $H v \mathrm{LD}$ structures presented here or in previously published PUL-oligosaccharide structures. A main 
feature for avoidance of $\alpha-1,4$-hydrolytic activity and strong preference for $\alpha$-1,6-hydrolytic activity in $H v \mathrm{LD}$ thereby seems to be based on the strong interaction to Trp512 and Phe553 on each flank of the catalytic cleft, which will keep non-branched polysaccharides out of the reach of the catalytic nucleophile and acid-base catalyst and at the same time position $\alpha$-1,6-branched substrates optimally for $\alpha-1,6$-hydrolysis to take place.

\section{Materials and methods}

\section{Sources of oligosaccharides}

G2S $\beta C D$ was synthesized via a route inspired by Greffe et al. [41]. G2S $\beta C D$ was treated with the maltogenic $\alpha$-amylase from Bacillus stearothermophilus (Novamyl [42], Sigma A2986) and the products $\mathrm{G}_{2} \mathrm{SG}^{2} 4$ and $\mathrm{G} 2 \mathrm{SG}^{2} 3$ were purified and partly separated by peracetylation followed by silicagel column chromatography and subsequent deprotection with sodium methoxide in $\mathrm{MeOH}$. $\mathrm{GG}^{2} 3 \mathrm{G}^{2} 3$ was from Megazyme, while $\mathrm{G}_{3} \mathrm{G}^{1} 3$ was a gift from the late Bent S. Enevoldsen.

\section{Recombinant HvLD expression in Escherichia coli}

A synthetic gene for $H v L D$, which was codon optimized for expression in Escherichia coli (E. coli), was bought from Genscript. The protein sequence was identical to the sequence published with previous studies (Uniprot id. Q9FYY0_HORVU) [18,19]. The gene was cloned into a pET28a vector (Novagen) using the Nde I and EcoR I restriction sites, which leads to the $H v L D$ being expressed with an N-terminal 6xHis-tag. This construct was used to produce the wild type $H v \mathrm{LD}$ and the $H v \mathrm{LD}-$ E510A variant. The point mutation leading to the $H v$ LD-E510A variant was introduced by PCR amplification of the expression plasmid using primers containing the nucleotide substitution (forward primer: 5'-CTGTACGGCGCAGGTTGGGATTTTGCTGAAGTG-3' and reverse primer: 5'CAAAATCCCAACCTGCGCCGTACAGATAGATTTTAGAGCC-3') and the QuickChange protocol (Stratagene). The plasmid was transformed into E. coli BL21(DE3) gold cells (Agilent Technologies). Protein expression was done using the T7 RNA polymerase based system [27] using standard procedures. Expression was induced by addition of isopropyl- $\beta$-D-thiogalactopyranoside to a final concentration of $0.5 \mathrm{mM}$. Induction was continued at $18^{\circ} \mathrm{C}$ and $180 \mathrm{rpm}$ overnight. The $H \nu \mathrm{LD}-\mathrm{M} 440 \mathrm{G}$ variant was obtained using the pPIC9K/LD construct as template [31] and the QuikChange Lightning Site-Directed Mutagenesis Kit (Stratagene) with forward primer: 5'GCCAGATTGAGAACAGTGCAGCTGGTAACAATACAGCAAGTGAGC-3' and reverse primer: 
5'- GCTCACTTGCTGTATTGTTACCAGCTGCACTGTTCTCAATCTGGC-3'. Transformation into Pichia pastoris strain GS115, selection for expression and secretion of $H v L D$ and recombinant production were done essentially as previously described [31].

\section{Purification of $\mathrm{HvLD}$}

E. coli cells were suspended in $20 \mathrm{mM}$ Na-phosphate, $30 \mathrm{mM}$ imidazole, $2 \mathrm{mM} \mathrm{MgCl}_{2}, 10 \mathrm{mM} \mathrm{NaCl}$, pH 7.4. One drop of anti-foam 204 (Sigma A6426) was added followed by cell lysis using a continuous cell disruptor (Constant Systems Ltd) operated at $1.35 \mathrm{kbar}$. The disrupted cells were sonicated on ice followed by addition of Benzonase (Sigma E1014) to a final concentration of $17 \mathrm{U} / \mathrm{ml}$ and $\mathrm{NaCl}$ to a final concentration of $500 \mathrm{mM}$. The cell lysate was centrifuged at $30000 \times \mathrm{g}$ for $20 \mathrm{~min}$ at $4^{\circ} \mathrm{C}$. The supernatant was collected and loaded onto a $5 \mathrm{ml}$ HisTrap FF crude affinity chromatography column (all columns were from GE Healthcare, Uppsala, Sweden) equilibrated with buffer A (20 mM sodium phosphate, $30 \mathrm{mM}$ imidazole, $500 \mathrm{mM} \mathrm{NaCl}$, pH 7.4) at a flow rate of $3 \mathrm{ml} / \mathrm{min}$. Elution was done with a $0-25 \%$ gradient of buffer B (20 mM sodium phosphate, $500 \mathrm{mM}$ imidazole, $500 \mathrm{mM} \mathrm{NaCl}, \mathrm{pH} 7.4)$ over 20 column volumes. The limit dextrinase containing fractions were pooled and ammonium sulfate was added to a concentration of $0.5 \mathrm{M}$. The pooled fractions were loaded onto a HiScreen phenyl HP column equilibrated in buffer A2 $\left(20 \mathrm{mM}\right.$ Bis-Tris, $\left.0.8 \mathrm{M}\left(\mathrm{NH}_{4}\right)_{2} \mathrm{SO}_{4}, \mathrm{pH} 7.0\right)$. Elution of $H v \mathrm{LD}$ was done with a gradient from 0 to $100 \%$ of Buffer B2 (20 mM Bis-Tris, pH 7.0) over 20 column volumes. The $H v$ LD containing fractions were pooled and concentrated (30 kDa MWCO Vivaspin20, SatoriusStedim). The concentrated HvLD sample was loaded onto a HiLoad Superdex 200 26/60 pg column, which was equilibrated in $20 \mathrm{mM} \mathrm{MES,} 150 \mathrm{mM} \mathrm{NaCl}$, pH 6.6. Fractions containing $H v L D$ were again pooled and this time concentrated (Amicon Ultra $0.5 \mathrm{ml} 30 \mathrm{kDa}$ MWCO, Millipore) to $20 \mathrm{mg} / \mathrm{ml}$ and stored at $-80^{\circ} \mathrm{C}$. $H v$ LD-M440G variant produced in $P$. pastoris was purified as previously described [18].

$H \nu \mathrm{LD}$ concentration was determined using the absorbance at $280 \mathrm{~nm}$ and $\varepsilon_{280 \mathrm{~nm}}=1.52 \times 10^{5} \mathrm{M}^{-1} \mathrm{~cm}^{-1}$ [31] and a molecular weight of $99.6 \mathrm{kDa}$. The specific activity of wild type $H v \mathrm{LD}$ was measured using the Limit Dextrizyme assay from Megazyme. The residual activity of the HvLD-E510A variant was determined using the reducing sugar assay as previously described [31] with $0.3 \mathrm{mg} / \mathrm{ml}$ pullulan (Megazyme) as substrate and $1 \mathrm{mM}$ of $H v \mathrm{LD}-\mathrm{E} 510 \mathrm{~A}$ or $3 \mathrm{nM}$ wild type $H v \mathrm{LD}$. The assay time for the $H v \mathrm{LD}$ variant was $26 \mathrm{hrs}$, while it was 15 min for wild type enzyme.

\section{Enzyme kinetics}


The kinetic constants of wild type $H v \mathrm{LD}$ and $H v \mathrm{LD}-\mathrm{M} 440 \mathrm{G}$ on different substrates were determined from initial hydrolysis velocities at $37^{\circ} \mathrm{C}$ using a reducing sugar assay [31]. The substrate concentrations were $0.02-1 \mathrm{mg} / \mathrm{ml}$ pullulan (Megazyme) or $0.5-10 \mathrm{mg} / \mathrm{ml}$ potato amylopectin (SigmaAldrich) and the enzyme concentration was $3.6 \mathrm{nM}$ wild type $H v \mathrm{LD}$ in the pullulan experiment and $25.7 \mathrm{nM}$ wild-type $H \nu \mathrm{LD}$ in the amylopectin experiment. The concentrations of $H v \mathrm{LD}-\mathrm{M} 440 \mathrm{G}$ were $3.6 \mathrm{nM}$ and $102.8 \mathrm{nM}$ in the pullulan and amylopectin experiment, respectively. In short, the starting volume of the assay was $1.1 \mathrm{ml}$ including substrate and enzyme in assay buffer. Aliquots $(200 \mu 1$ in case of pullulan and $100 \mu \mathrm{l}$ in case of amylopectin) were removed at five time points $(3,6,9,12$, and $15 \mathrm{~min}$ ) and added to $500 \mu \mathrm{l}$ stop solution. Milli-Q water was then added to a final volume of $1 \mathrm{ml}$. The absorbance at $\lambda=540 \mathrm{~nm}$ was measured after $30 \mathrm{~min}$ incubation at $80^{\circ} \mathrm{C}$. The release of reducing sugar was quantified using a maltose standard curve $(0-55.5 \mu \mathrm{M})$. The Michaelis constant, $K_{\mathrm{m}}$, and the catalytic constant/turnover number, $k_{\mathrm{cat}}$, were determined by fitting the Michaelis-Menten equation to the initial velocities. The fitting and plotting were done using the Enzyme Kinetics Module 1.0 of the program Sigmaplot 9.01 (Systat Software, Chicago, IL).

\section{Crystallization and data collection}

Crystallization was based on previously published conditions [19]. The protein was first diluted to 10 $\mathrm{mg} / \mathrm{ml}$ with $20 \mathrm{mM}$ MES, $150 \mathrm{mM} \mathrm{NaCl}, \mathrm{pH} 6.6$ and $5 \mathrm{mM}$ DTT and crystals were grown using the hanging drop vapor diffusion method. The drops were $2 \mu \mathrm{L}$ of protein solution added 1.5 or $2 \mu \mathrm{L}$ of reservoir solution. In the case of $\mathrm{G} 2 \mathrm{~S} \beta \mathrm{CD}$ or the low concentration $\mathrm{G} 3 / \mathrm{G} 4$ co-crystallization experiments, the dilution buffer also contained $0.8 \mathrm{mM} \mathrm{G} 2 \mathrm{~S} \beta \mathrm{CD}$ or a mixture of $25 \mathrm{mM} \mathrm{G} 3$ and 25 $\mathrm{mM}$ G4, respectively. The reservoir solution contained 19\% (w/v) PEG3350, 0.3 M NaI and in the case of $\mathrm{G} 2 \mathrm{~S} \beta \mathrm{CD}, 5 \%(\mathrm{v} / \mathrm{v})$ glycerol. The drops were streaked seeded. Crystallization trays were stored at $20^{\circ} \mathrm{C}$, and crystals appeared after 4-7 days. The crystals were cryo-protected using paratone oil (Hampton Research). No cryo-protectant was used for the $300 \mathrm{mM} \mathrm{G} 4$ soak. In the case of the G2SG ${ }^{2} 4$, $\mathrm{GG}^{2} 3 \mathrm{G}^{2} 3$ and $\mathrm{G}^{3} \mathrm{G}^{1} 3 \mathrm{HvLD}$ complex structures, $50-100 \mathrm{mM}$ of each compound was made up in reservoir solution and added directly into the crystal drop for a final concentration of 25-50 $\mathrm{mM}$ oligosaccharide. After an incubation period of 15-60 min at room temperature, the crystals were cryoprotected with paratone oil and flash cooled in liquid nitrogen. Diffraction data were collected on either beam line I911-2 at MAX II Laboratory in Lund, Sweden, or on beam line ID23-1 at the European Synchrotron Radiation Facility (ESRF) in Grenoble, France (Table 1). 


\section{Structure determination and Refinement}

The diffraction data were processed and scaled using XDS [43] or iMOSFLM [44] combined with SCALA from the CCP4 program suite [45,46]. Molecular replacement was performed using MOLREP [47] from the CCP4 program suite with the HvLD- $\beta$-CD structure (PDB entry 2Y4S [19]) as the starting model. After molecular replacement, cycles of restrained refinement with REFMAC5 [48] were alternated with manual inspection, rebuilding, and addition of water molecules, ligands and ions using Coot [49]. Anisotropic B-factor refinement was applied at the near-end cycles of refinement. The final structure validation and analysis of model geometry optimization were performed using the output from PROCHECK [50] and Molprobity [51]. The final statistics for data processing and structure refinement are given in Table 1. PyMOL (The PyMOL Molecular Graphics System, Schrödinger, LLC) was used for the visualization of the structures.

\section{Database linking}

PDB: 4J3S, PDB: 4J3T, PDB: 4J3U, PDB: 4J3V, PDB: $4 J 3 \mathrm{~W}, P D B: 4 J 3 X$

\section{Accession numbers}

Coordinates and structure factors have been deposited in the PDB under RCSD PDB accession codes 4J3S, 4J3T, 4J3U, 4J3 V, 4J3W, 4J3X.

\section{Acknowledgements}

Access to synchrotron beam time was made possible through the support from DANSCATT. MAX II Laboratory, ESRF and the associated staff at the beam lines are acknowledged for provision of synchrotron beam time and assistance. Madhuri Kyasaram, Technical University of Denmark is thanked for help and assistance with production and purification of the $H v \mathrm{LD}$ M440 variant. 


\section{Figure captions}

Figure 1. (a) Overall structure of $H v \mathrm{LD}-\mathrm{E} 510 \mathrm{~A}$ in complex with $\mathrm{G} 3 \mathrm{G}^{1} 3$. N-domain, red; carbohydrate binding module 48, yellow; catalytic domain, gray; C-domain, blue; $\mathrm{Ca}^{2+}$, purple; I', orange. The ligand is shown as green sticks. (b) The active site residues of $H v \mathrm{LD}$ (grey sticks) interacting with the substrate (green sticks), the general acid/base of $H v \mathrm{LD}$ (Glu510) is mutated to an alanine, but two water molecules (grey spheres) are situated at positions corresponding to the carboxylic oxygen atoms of the original general acid/base catalyst. (c) Superimposition of the three catalytic residues of $H \nu \mathrm{LD}-\mathrm{G}_{3} \mathrm{G}^{1} 3$ and uncomplexed $H \nu \mathrm{LD}$ (PDB entry 4AIO; orange sticks). Same color code as in (b).

Figure 2. Schematic illustration of subsite nomenclature used in this study and adapted from Davies et al. and Mikami et al. [20,26]. Each subsite interacts with one glucosyl unit. The carbohydrate main chain is bound at subsites $-1^{\prime}, 0^{\prime},+1,+2,+3$ etcetera, while the branch is bound at the $-3,-2,-1$ subsites. The scissile $\alpha-1,6$ bond of the branched substrate is placed between subsites -1 and +1 . The crossed out hexagon shows the reducing end of the polysaccharide.

Figure 3. Details on subsite interactions of $H \nu \mathrm{LD}$. Yellow sticks, $H v \mathrm{LD}-\mathrm{E} 510 \mathrm{~A}-\mathrm{G} 3 \mathrm{G}^{1} 3$; turquoise sticks, $H v \mathrm{LD}-\mathrm{E} 510 \mathrm{~A}-\mathrm{GG}^{2} 3 \mathrm{G}^{2} 3$; purple sticks, $H v \mathrm{LD}-\mathrm{G} 4(300 \mathrm{mM})$; orange sticks, $H v \mathrm{LD}-\mathrm{G} 4(25$ $\mathrm{mM}$ ); magenta sticks, $H v \mathrm{LD}-\mathrm{G} 2 \mathrm{~S} \beta \mathrm{CD}$, green sticks, $\left.H v \mathrm{LD}-\mathrm{G}_{2} \mathrm{SG}^{2} 4\right)$. (a) close up on the active site cleft of $H v \mathrm{LD}-\mathrm{E} 510 \mathrm{~A}-\mathrm{G} 3 \mathrm{G}^{1} 3$, (b) $H v \mathrm{LD}-\mathrm{E} 510 \mathrm{~A}-\mathrm{GG}^{2} 3 \mathrm{G}^{2} 3$, (c) $H v \mathrm{LD}-\mathrm{G} 4(25 \mathrm{mM}$ ), (d) $H v \mathrm{LD}-\mathrm{G} 4$ (300 mM), (e) $H v \mathrm{LD}-\mathrm{G} 2 \mathrm{SG}^{2} 4$ and (f) $H \nu \mathrm{LD}-\mathrm{G} 2 \mathrm{~S} \beta \mathrm{CD}$.

Figure 4. (a) Stereo representation of the superimposition of the active site of $H v \mathrm{LD}-\mathrm{G}_{3} \mathrm{G}^{1} 3$ (cyan) with the HvAMY1 D180A active site with maltoheptaose bound (orange, PDB code 1RP8) shows that $H v \mathrm{LD}$ branch binding sites -1 and -2 closely resembles the -1 and -2 subsites in HvAMY1. (b) Comparison of the hydrogen bonding pattern of $H v \mathrm{LD}$ His 404 from $H v \mathrm{LD}-\mathrm{G} 3 \mathrm{G}^{1} 3$ (grey), $H v \mathrm{LD}-$ $\mathrm{GG}^{2} 3 \mathrm{G}^{2} 3$ (cyan), and $H \nu \mathrm{LD}-\beta \mathrm{CD}$ (PDB entry $2 \mathrm{Y} 4 \mathrm{~S}$; purple). The hydrogen bonds of His 404 are likely to play a role for the reactivity of the catalytic nucleophile. (c) Superimposition of the active site around subsite -1 of $H v \mathrm{LD}-\mathrm{E} 510 \mathrm{~A}$ in complex $\mathrm{G}^{1} \mathrm{G}^{1} 3$ (grey) and $H v \mathrm{LD}-\mathrm{E} 510 \mathrm{~A}$ in complex with $\mathrm{GG}^{2} 3 \mathrm{G}^{2} 3$ (cyan).

Figure 5. The phenylalanine in subsite +2 of $H v \mathrm{LD}$ (Phe553, yellow) and $K p \mathrm{PUL}$ (Phe746, blue) is to some extent flexible and substrate sandwiching between Trp512 (Trp708 of KpPUL) and Phe553 
seems to favor main chain binding to the $+2,+1,0$ ' subsites too remote from the active site nucleophile and acid/base catalyst to allow hydrolysis of the $\alpha-1,4$-bond of the main chain. 


\section{References}

[1] Buleon A, Colonna P, Planchot V, Ball S. Starch granules: structure and biosynthesis. Int J Biol Macromol 1998;23:85-112.

[2] Kays SJ. Secondary metabolic processes and products. In: Secondary metabolic processes and products 1991; pp. 143-256, Van Nostrand Reinhold, New York.

[3] Kristensen M, Lok F, Planchot V, Svendsen I, Leah R, Svensson B. Isolation and characterization of the gene encoding the starch debranching enzyme limit dextrinase from germinating barley. Biochim Biophys Acta 1999;1431:538-46.

[4] Kristensen M, Planchot V, Abe J, Svensson B. Large-scale purification and characterization of barley limit dextrinase, a member of the $\alpha$-amylase structural family. Cereal Chem 1998;75:4739.

[5] Sissons MJ, Taylor M, Proudlove M. Barley malt limit dextrinase: Its extraction, heat stability and activity during malting and mashing. J Am Soc Brew Chem 1995;53:105-10.

[6] Evans DE, Damsberg R, Ratkowsky D, Li C, Harasymow S, Roumeliotis S, Eglinton JK. Refining the prediction of potential malt fermentability by including an assessment of limit dextrinase thermostability and additional measures of malt modification, using two different methods for multivariate model development. J Inst Brew 2010;116:86-96.

[7] McCafferty CA, Jenkinson HR, Brosnan JM, Bryce JH. Does its malt activity relate to its activity during brewing? J Inst Brew 2004;110:284-96.

[8] Wang XD, Yang J, Zhang GP. Genotypic and environmental variation in barley limit dextrinase activity and its relation to malt quality. J Zhejiang Univ Sci B 2006;7:386-92.

[9] Stenholm K, Home S. A new approach to limit dextrinase and its role in mashing. J Inst Brew 1999;105:205-10.

[10] Dinges JR, Colleoni C, James MG, Myers AM. Mutational analysis of the pullulanase-type debranching enzyme of maize indicates multiple functions in starch metabolism. Plant Cell 2003; 15:666-80.

[11] Cantarel BL, Coutinho PM, Rancurel C, Bernard T, Lombard V, Henrissat B. The CarbohydrateActive EnZymes database (CAZy): an expert resource for glycogenomics. Nucleic Acids Res 2009;37:D233-D238.

[12] Stam MR, Danchin EG, Rancurel C, Coutinho PM, Henrissat B. Dividing the large glycoside hydrolase family 13 into subfamilies: towards improved functional annotations of $\alpha$-amylaserelated proteins. Protein Eng Des Sel 2006;19:555-62. 
[13] Singh RS, Saini GK, Kennedy JF. Pullulan: Microbial sources, production and applications. Carbohydr Polym 2008;73:515-31.

[14] Uitdehaag JC, Mosi R, Kalk KH, van der Veen BA, Dijkhuizen L, Withers SG, Dijkstra BW. Xray structures along the reaction pathway of cyclodextrin glycosyltransferase elucidate catalysis in the $\alpha$-amylase family. Nat Struct Biol 1999;6:432-6.

[15] Davies G, Henrissat B. Structures and mechanisms of glycosyl hydrolases. Structure 1995;3:8539.

[16] MacGregor EA, Janecek S, Svensson B. Relationship of sequence and structure to specificity in the $\alpha$-amylase family of enzymes. Biochim Biophys Acta 2001;1546:1-20.

[17] MacGregor EA. An overview of clan GH-H and distantly-related families. Biologia 2005;60:512.

[18] Møller MS, Abou Hachem M, Svensson B, Henriksen A. Structure of the starch-debranching enzyme barley limit dextrinase reveals homology of the N-terminal domain to CBM21. Acta Crystallogr Sect F Struct Biol Cryst Commun 2012;68:1008-12.

[19] Vester-Christensen MB, Abou Hachem M, Svensson B, Henriksen A. Crystal structure of an essential enzyme in seed starch degradation: barley limit dextrinase in complex with cyclodextrins. J Mol Biol 2010;403:739-50.

[20] Mikami B, Iwamoto H, Malle D, Yoon HJ, Demirkan-Sarikaya E, Mezaki Y, Katsuya Y. Crystal structure of pullulanase: evidence for parallel binding of oligosaccharides in the active site. J Mol Biol 2006;359:690-707.

[21] Gourlay LJ, Santi I, Pezzicoli A, Grandi G, Soriani M, Bolognesi M. Group B Streptococcus pullulanase crystal structures in the context of a novel strategy for vaccine development. J Bacteriol 2009;191:3544-52.

[22] Lammerts van Bueren A, Ficko-Blean E, Pluvinage B, Hehemann JH, Higgins MA, Deng L, Ogunniyi AD, Stroeher UH, El WN, Burke RD, Czjzek M, Paton JC, Vocadlo DJ, Boraston AB. The conformation and function of a multimodular glycogen-degrading pneumococcal virulence factor. Structure 2011;19:640-51.

[23] Malle D, Itoh T, Hashimoto W, Murata K, Utsumi S, Mikami B. Overexpression, purification and preliminary X-ray analysis of pullulanase from Bacillus subtilis strain 168. Acta Crystallogr F Struct Biol Cryst Commun 2006;62:381-4.

[24] Turkenburg JP, Brzozowski AM, Svendsen A, Borchert TV, Davies GJ, Wilson KS. Structure of a pullulanase from Bacillus acidopullulyticus. Proteins 2009;76:516-9. 
[25] Xu J, Ren F, Huang CH, Zheng Y, Zhen J, Sun H, Ko TP, He M, Chen CC, Chan HC, Guo RT, Song H, Ma Y. Functional and structural studies of pullulanase from Anoxybacillus sp. LM18-11. Proteins 2013;82:1685-93.

[26] Davies GJ, Wilson KS, Henrissat B. Nomenclature for sugar-binding subsites in glycosyl hydrolases. Biochem J 1997;321:557-9.

[27] Studier FW, Rosenberg AH, Dunn JJ, Dubendorff JW. Use of T7 RNA polymerase to direct expression of cloned genes. Methods Enzymol 1990;185:60-89.

[28] Jensen, MT. Structure and function of barley limit dextrinase and mutational analysis of barley $\alpha-$ amylase isozyme differences and interaction with branched oligosaccharides 2002; Ph.D. Thesis, University of Southern Denmark, Odense.

[29] Kumar V. Analysis of the key active subsites of glycoside hydrolase 13 family members. Carbohydr Res 2010;345:893-8.

[30] Greffe L, Jensen MT, Bosso C, Svensson B, Driguez H. Chemoenzymatic synthesis of branched oligo- and polysaccharides as potential substrates for starch active enzymes. Chembiochem 2003;4:1307-11.

[31] Vester-Christensen MB, Abou Hachem M, Naested H, Svensson B. Secretory expression of functional barley limit dextrinase by Pichia pastoris using high cell-density fermentation. Protein Expr Purif 2010;69:112-9.

[32] Robert X, Haser R, Mori H, Svensson B, Aghajari N. Oligosaccharide binding to barley $\alpha$ amylase 1. J Biol Chem 2005;280:32968-78.

[33] Hasegawa K, Kubota M, Matsuura Y. Roles of catalytic residues in $\alpha$-amylases as evidenced by the structures of the product-complexed mutants of a maltotetraose-forming amylase. Protein Eng 1999;12:819-24.

[34] Yamashita M, Matsumoto D, Murooka Y. Amino acid residues specific for the catalytic action towards $\alpha-1,6$-glucosidic linkages in Klebsiella pullulanase. J Ferment Bioeng 1997;84:283-90.

[35] Robert X, Haser R, Gottschalk TE, Ratajczak F, Driguez H, Svensson B, Aghajari N. The structure of barley $\alpha$-amylase isozyme 1 reveals a novel role of domain $\mathrm{C}$ in substrate recognition and binding: a pair of sugar tongs. Structure 2003;11:973-84.

[36] Kadziola A, Sogaard M, Svensson B, Haser R. Molecular structure of a barley alpha-amylaseinhibitor complex: implications for starch binding and catalysis. J Mol Biol 1998;278:205-17.

[37] Manners DJ, Yellowlees D. Studies on carbohydrate metabolising enzymes. Part XXVI. Limit dextrinase from germinated barley. Starch-Starke 1971;23:228-34. 
[38] Hardie DG, Manners DJ, Yellowlees D. The limit dextrinase from malted sorghum (Sorghum vulgare). Carbohydr Res 1976;50:75-85.

[39] Yellowlees D. Purification and characterisation of limit dextrinase from Pisum sativum L. Carbohydr Res 1980;83:109-18.

[40] Hii SL, Tan JS, Ling TC, Ariff AB. Pullulanase: role in starch hydrolysis and potential industrial applications. Enzyme Res 2012;921362:1-14.

[41] Greffe L, Jensen MT, Chang-Pi-Hin F, Fruchard S, O'Donohue MJ, Svensson B, Driguez H. Chemoenzymatic syntheses of linear and branched hemithiomaltodextrins as potential inhibitors for starch-debranching enzymes. Chem Eur J 2002;8:5447-55.

[42] Jørgensen CT, Svendsen A, Brask J. Enzymatic synthesis of oligosaccharides from branched cyclodextrins. Carbohydr Res 2005;340:1233-7.

[43] Kabsch W. XDS. Acta Crystallogr D Biol Crystallogr 2010;66:125-32.

[44] Battye TG, Kontogiannis L, Johnson O, Powell HR, Leslie AG. iMOSFLM: a new graphical interface for diffraction-image processing with MOSFLM. Acta Crystallogr D Biol Crystallogr 2011;67:271-81.

[45] Winn MD, Ballard CC, Cowtan KD, Dodson EJ, Emsley P, Evans PR, Keegan RM, Krissinel EB, Leslie AG, McCoy A, McNicholas SJ, Murshudov GN, Pannu NS, Potterton EA, Powell HR, Read RJ, Vagin A, Wilson KS. Overview of the CCP4 suite and current developments. Acta Crystallogr D Biol Crystallogr 2011;67:235-42.

[46] Potterton E, Briggs P, Turkenburg M, Dodson E. A graphical user interface to the CCP4 program suite. Acta Crystallogr D Biol Crystallogr 2003;59:1131-7.

[47] Vagin A, Teplyakov A. Molecular replacement with MOLREP. Acta Crystallogr D Biol Crystallogr 2010;66:22-5.

[48] Murshudov GN, Skubak P, Lebedev AA, Pannu NS, Steiner RA, Nicholls RA, Winn MD, Long F, Vagin AA. REFMAC5 for the refinement of macromolecular crystal structures. Acta Crystallogr D Biol Crystallogr 2011;67:355-67.

[49] Emsley P, Lohkamp B, Scott WG, Cowtan K. Features and development of Coot. Acta Crystallogr D Biol Crystallogr 2010;66:486-501.

[50] Laskowski RA, MacArthur MW, Moss DS, Thornton JM. Procheck: a program to check the stereochemical quality of protein structures. J Appl Crystallogr 1993;26:283-91.

[51] Chen VB, Arendall WB, III, Headd JJ, Keedy DA, Immormino RM, Kapral GJ, Murray LW, Richardson JS, Richardson DC. MolProbity: all-atom structure validation for macromolecular crystallography. Acta Crystallogr D Biol Crystallogr 2010;66:12-21. 
Tables

Table 1. Data collection and refinement statistics.

\begin{tabular}{|c|c|c|c|c|c|c|}
\hline & $\begin{array}{l}H \nu \mathrm{LD}- \\
\mathrm{G} 2 \mathrm{~S} \beta \mathrm{CD} \\
(0.8 \mathrm{mM})\end{array}$ & $\begin{array}{l}H v \mathrm{LD}_{-} \\
\mathrm{G}^{2} \mathrm{SG}^{2} 4 \\
(25-50 \\
\mathrm{mM})\end{array}$ & $\begin{array}{l}H v \mathrm{LD}-\mathrm{G} 4 \\
(25 \mathrm{mM})\end{array}$ & $\begin{array}{l}H \nu \mathrm{LD}-\mathrm{G} 4 \\
(300 \mathrm{mM})\end{array}$ & $\begin{array}{l}v \mathrm{LD}- \\
\mathrm{E} 510 \mathrm{~A}- \\
\mathrm{GG}^{2} 3-\mathrm{G}^{2} 3 \\
(25-50 \\
\mathrm{mM})\end{array}$ & $\begin{array}{l}H v \text { LD- } \\
\text { E510A- } \\
\text { G3G } 3 \\
(25-50 \\
\mathrm{mM})\end{array}$ \\
\hline$P D B I D$ & $4 J 3 U$ & $4 J 3 V$ & $4 J 3 T$ & $4 J 3 S$ & $4 J 3 X$ & $4 J 3 W$ \\
\hline \multicolumn{7}{|l|}{ ligand } \\
\hline \multicolumn{7}{|l|}{ Data Collection } \\
\hline X-ray source & $\begin{array}{l}\text { Max-lab II } \\
(\mathrm{I} 911-2)\end{array}$ & $\begin{array}{l}\text { Max-lab II } \\
(\mathrm{I} 911-2)\end{array}$ & $\begin{array}{l}\text { Max-lab II } \\
(\text { I911-2) }\end{array}$ & $\begin{array}{l}\text { ESRF } \\
\text { (ID23-1) }\end{array}$ & $\begin{array}{l}\text { Max-lab II } \\
\text { (I911-2) }\end{array}$ & $\begin{array}{l}\text { Max-lab II } \\
(\mathrm{I} 911-2)\end{array}$ \\
\hline Wavelength $(\AA)$ & 1.04 & 1.04 & 1.04 & 0.992 & 1.04 & 1.04 \\
\hline Space group & $\mathrm{C} 2$ & $\mathrm{C} 2$ & $\mathrm{C} 2$ & $\mathrm{C} 2$ & $\mathrm{C} 2$ & $\mathrm{C} 2$ \\
\hline \multicolumn{7}{|c|}{ Unit cell parameters } \\
\hline$a(\AA)$ & 195.4 & 174.0 & 175.1 & 169.3 & 173.3 & 168.9 \\
\hline$b(\AA)$ & 84.6 & 85.8 & 86.2 & 81.2 & 86.2 & 80.9 \\
\hline$c(\AA)$ & 121.8 & 61.6 & 61.5 & 58.2 & 61.6 & 58.3 \\
\hline$\beta\left(^{\circ}\right)$ & 119.9 & 96.0 & 95.6 & 101.1 & 96.0 & 100.8 \\
\hline $\begin{array}{l}\text { Resolution limit } \\
(\AA)\end{array}$ & $\begin{array}{l}29.8-1.70 \\
(1.79-1.70 \\
)^{\mathrm{a}} \\
\end{array}$ & $\begin{array}{l}28.9-1.45 \\
(1.53-1.45)\end{array}$ & $\begin{array}{l}29.7-1.60 \\
(1.69-1.60 \\
) \\
\end{array}$ & $\begin{array}{l}47.0-1.75 \\
(1.84-1.75)\end{array}$ & $\begin{array}{l}28.34-1.75 \\
(1.84-1.75 \\
) \\
\end{array}$ & $\begin{array}{l}22.8-1.67 \\
(1.71-1.67)\end{array}$ \\
\hline $\begin{array}{l}\text { Measured } \\
\text { reflections }\end{array}$ & $\begin{array}{l}709830 \\
(111373)\end{array}$ & $\begin{array}{l}593476 \\
(92492) \\
\end{array}$ & $\begin{array}{l}447388 \\
(68281) \\
\end{array}$ & $\begin{array}{l}247971 \\
(38495)\end{array}$ & $\begin{array}{l}263179 \\
(39923)\end{array}$ & $\begin{array}{l}420337 \\
(42726) \\
\end{array}$ \\
\hline Unique reflections & $\begin{array}{l}188337 \\
(30059) \\
\end{array}$ & $\begin{array}{l}158107 \\
(25202) \\
\end{array}$ & $\begin{array}{l}119395 \\
(18764) \\
\end{array}$ & $\begin{array}{l}77622 \\
(12233) \\
\end{array}$ & \begin{tabular}{|l|}
89001 \\
$(14033)$ \\
\end{tabular} & $\begin{array}{l}89214 \\
(10649) \\
\end{array}$ \\
\hline Redundancy & $3.8(3.7)$ & $3.8(3.7)$ & $3.7(3.6)$ & $3.2(3.1)$ & $3.0(2.8)$ & $4.7(4.0)$ \\
\hline Completeness (\%) & $99.3(98.5)$ & $99.5(98.5)$ & $99.4(97.4)$ & $98.8(97.0)$ & $97.4(95.7)$ & $99.2(89.6)$ \\
\hline$(\mathrm{I}) / \sigma(\mathrm{I})$ & $11.7(2.6)$ & $15.3(3.2)$ & $14.5(3.4)$ & $14.4(2.8)$ & $12.0(2.4)$ & $12.0(3.7)$ \\
\hline$R_{\mathrm{sym}}(\%)$ & $7.6(51.5)$ & $5.6(48.8)$ & $6.3(39.7)$ & $6.0(47.8)$ & $7.6(53.7)$ & $7.9(35.2)$ \\
\hline$R_{\text {pim }}(\%)$ & $4.6(36.8)$ & $3.4(34.1)$ & $3.8(28.7)$ & $3.9(37.6)$ & $5.1(45.1)$ & $3.9(19.6)$ \\
\hline \multicolumn{7}{|l|}{ Refinement } \\
\hline Used reflections & $\begin{array}{l}188323 \\
(12748)\end{array}$ & $\begin{array}{l}158098 \\
(10608)\end{array}$ & $\begin{array}{l}119378 \\
(7798)\end{array}$ & $\begin{array}{l}77407 \\
(5287) \\
\end{array}$ & $\begin{array}{l}88989 \\
(5755) \\
\end{array}$ & $\begin{array}{l}89211 \\
(5475)\end{array}$ \\
\hline$R_{\text {cryst }} / R_{\text {free }}(\%)$ & $17.2 / 21.8$ & $12.0 / 16.7$ & $13.3 / 17.7$ & $13.6 / 18.2$ & $14.9 / 19.5$ & $16.4 / 19.6$ \\
\hline $\begin{array}{l}\text { Number mol. in } \\
\text { A.U. }\end{array}$ & 2 & 1 & 1 & 1 & 1 & 1 \\
\hline Protein atoms & 15402 & 8018 & 7897 & 7349 & 7931 & 7171 \\
\hline Water molecules & 1612 & 1069 & 1026 & 738 & 983 & 375 \\
\hline $\begin{array}{l}\text { No. Ligand } \\
\text { molecule }\end{array}$ & 2 & 2 & 1 & 3 & 1 & 1 \\
\hline Mean $B$-factor $\left(\AA^{2}\right)$ & & & & & & \\
\hline
\end{tabular}




\begin{tabular}{|l|l|l|l|l|l|l|}
\hline All atoms & 20.03 & 17.60 & 17.81 & 23.18 & 18.34 & 16.02 \\
\hline Protein atoms & $18.6 / 19.3^{\mathrm{c}}$ & 15.9 & 15.9 & 22.3 & 16.9 & 16.0 \\
\hline Ligand $(\mathrm{MC})^{\mathrm{b}}$ & $25.5 / 30.9^{\mathrm{c}}$ & 26.8 & 19.9 & 25.0 & $25.9^{\mathrm{d}}$ & $16.3^{\mathrm{d}}$ \\
\hline Ligand (SC) & $\mathrm{N} / \mathrm{A}$ & 23.9 & $\mathrm{~N} / \mathrm{A}$ & 36.5 & 25.9 & 16.4 \\
\hline Ligand (S) & $\mathrm{N} / \mathrm{A}$ & $\mathrm{N} / \mathrm{A}$ & $\mathrm{N} / \mathrm{A}$ & 29.2 & N/A & N/A \\
\hline Solvent & 28.0 & 31.1 & 27.8 & 31.7 & 27.8 & 18.9 \\
\hline $\begin{array}{l}\text { R.m.s.d. values } \\
\text { from ideal }\end{array}$ & & & & & & \\
\hline Bond lengths $(\AA)$ & 0.005 & 0.007 & 0.007 & 0.006 & 0.006 & 0.005 \\
\hline Bond angles $\left({ }^{\circ}\right)$ & 1.058 & 1.283 & 1.282 & 1.133 & 1.145 & 1.170 \\
\hline Ramachandran Plot & & & & & & \\
\hline $\begin{array}{c}\text { Preferred regions } \\
(\%)\end{array}$ & 96.9 & 96.4 & 97.0 & 97.6 & 97.2 & 97.3 \\
\hline $\begin{array}{c}\text { Allowed regions } \\
(\%)\end{array}$ & 2.8 & 3.1 & 2.7 & 2.2 & 2.5 & 2.5 \\
\hline Outliers $(\%)$ & 0.3 & 0.5 & 0.2 & 0.2 & 0.4 & 0.2 \\
\hline
\end{tabular}

${ }^{\mathrm{a}}$ Values in parentheses are for the highest resolution bin.

${ }^{\mathrm{b}}$ Ligand binding sites: MC, Main chain; SC, side-chain; S, surface site.

${ }^{c}$ Values are for protein or ligand associated with Chain A/ Chain B

${ }^{\mathrm{d}}$ Ligand spans both MC and SC binding site.

Table 2. Kinetic parameters of wild type $H v \mathrm{LD}$ and the $H v \mathrm{LD}-\mathrm{M} 440 \mathrm{G}$ variant

\begin{tabular}{lllll}
\hline & $\begin{array}{l}K_{\mathrm{m}} \\
(\mathrm{mg} / \mathrm{ml})\end{array}$ & $\begin{array}{l}k_{\text {cat }} \\
\left(\mathrm{s}^{-1}\right)\end{array}$ & $\begin{array}{l}k_{\text {cat }} / K_{\mathrm{m}} \\
(\mathrm{ml} /(\mathrm{mg} \mathrm{s}))\end{array}$ & $\begin{array}{l}K_{\mathrm{i}} \\
(\mathrm{mg} / \mathrm{ml})\end{array}$ \\
\hline Pullulan $^{\mathrm{a}}$ & & & & \\
Wild type $H \nu \mathrm{LD}$ & $0.16 \pm 0.02$ & $78 \pm 10$ & 488 & $1.5 \pm 0.4$ \\
$H \nu L D-M 440 \mathrm{G}$ & $0.15 \pm 0.06$ & $72 \pm 15$ & 480 & $1.7 \pm 1.1$ \\
$\begin{array}{c}\text { Amylopectin } \\
\text { W }\end{array}$ & & & & \\
Wild type $H \nu \mathrm{LD}$ & $6.9 \pm 1.0$ & $15.6 \pm 1.2$ & 2.3 & \\
$H \nu$ LD-M440G & $4.4 \pm 0.3$ & $3.9 \pm 0.1$ & 0.9 & \\
\hline
\end{tabular}

${ }^{\mathrm{a}}$ Uncompetitive substrate inhibition kinetic analysis.

${ }^{\mathrm{b}}$ Classical Michaelis-Menten kinetic analysis. 
(a)

Fig. 1
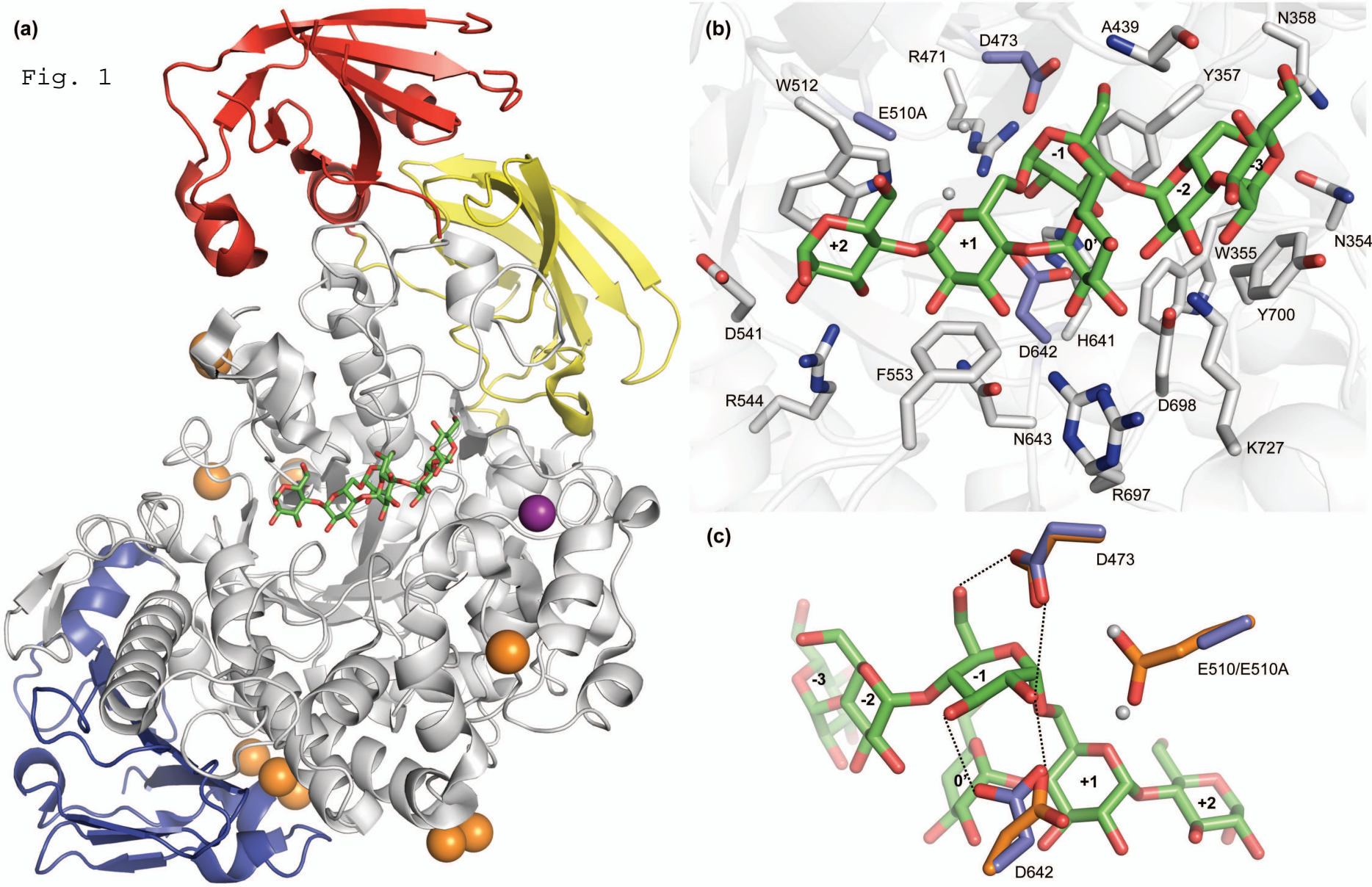


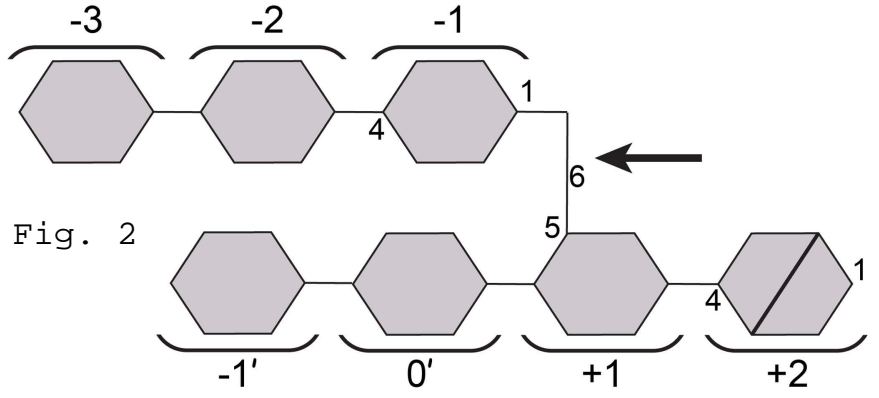




$$
\text { W512 }
$$

(b)
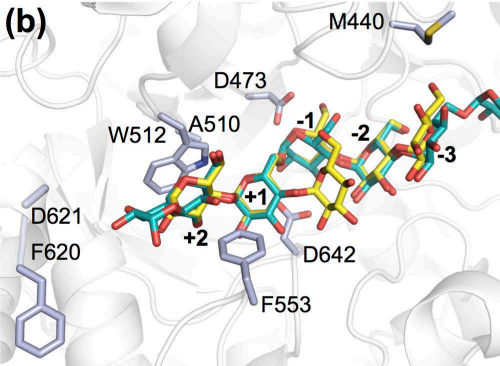

(c)

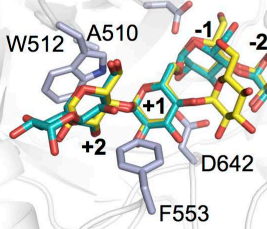

(d)

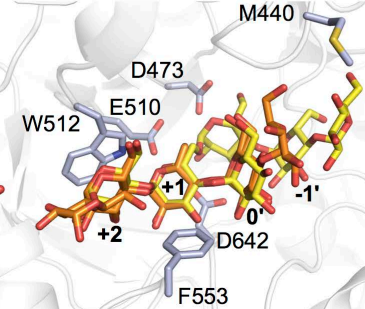

(e)

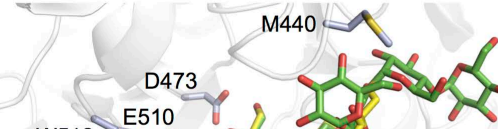
W512 E510 A

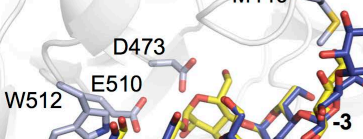

D621 F62

(f)

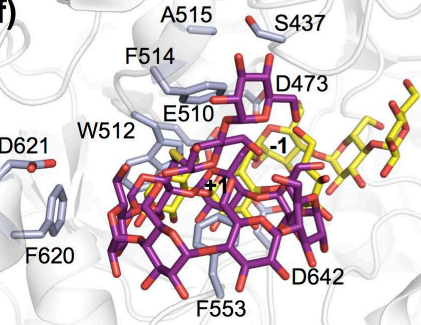

W512 A510

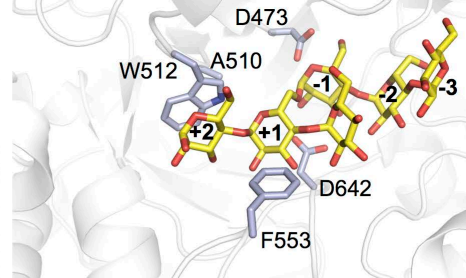

D621

F620

D)
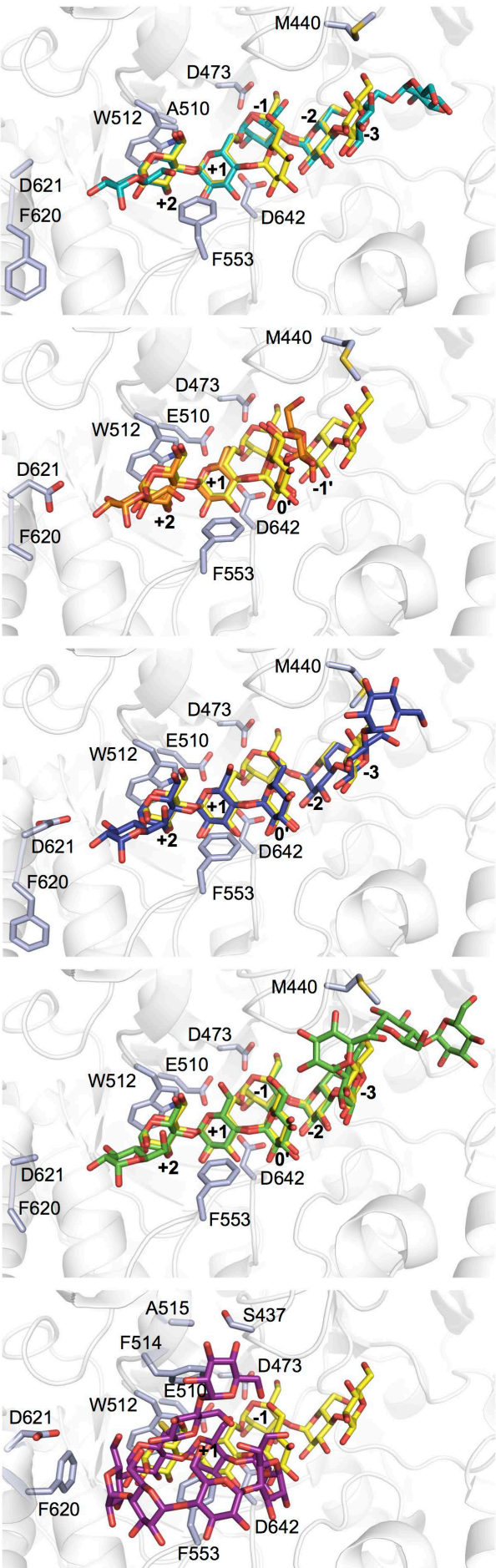
(a) Fig. ${ }_{\text {D473/A180 }}^{4}$

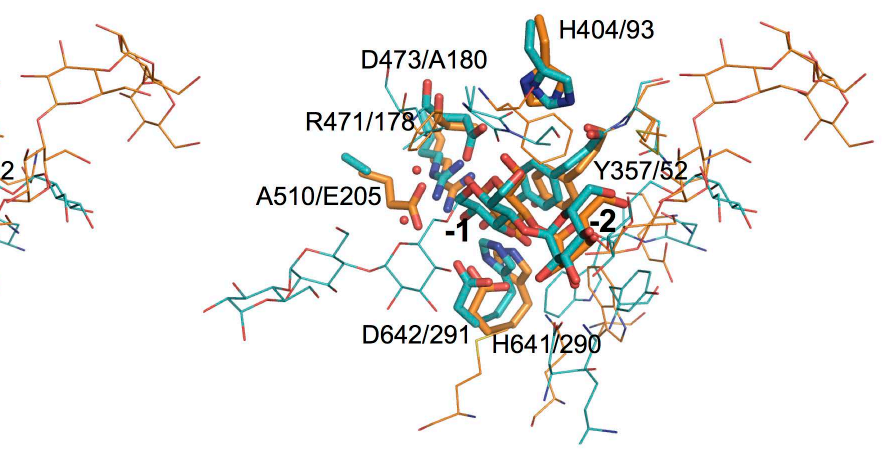

(b)

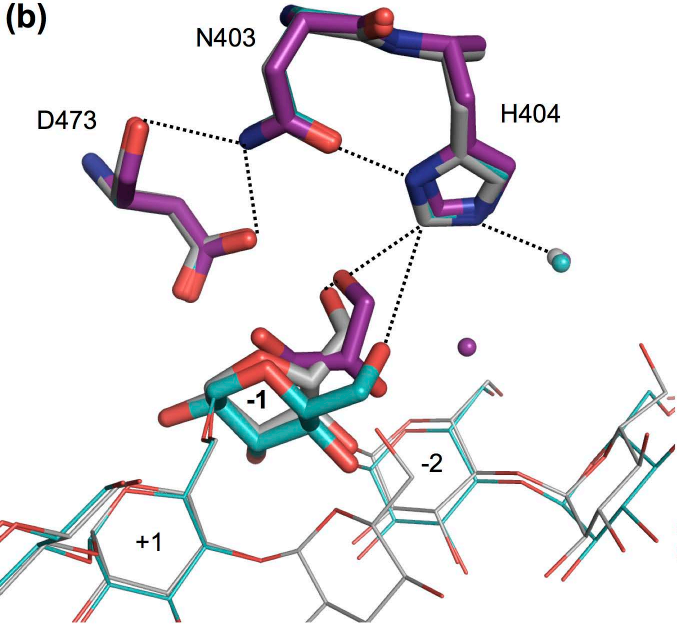

(c)
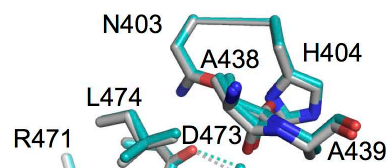

A510
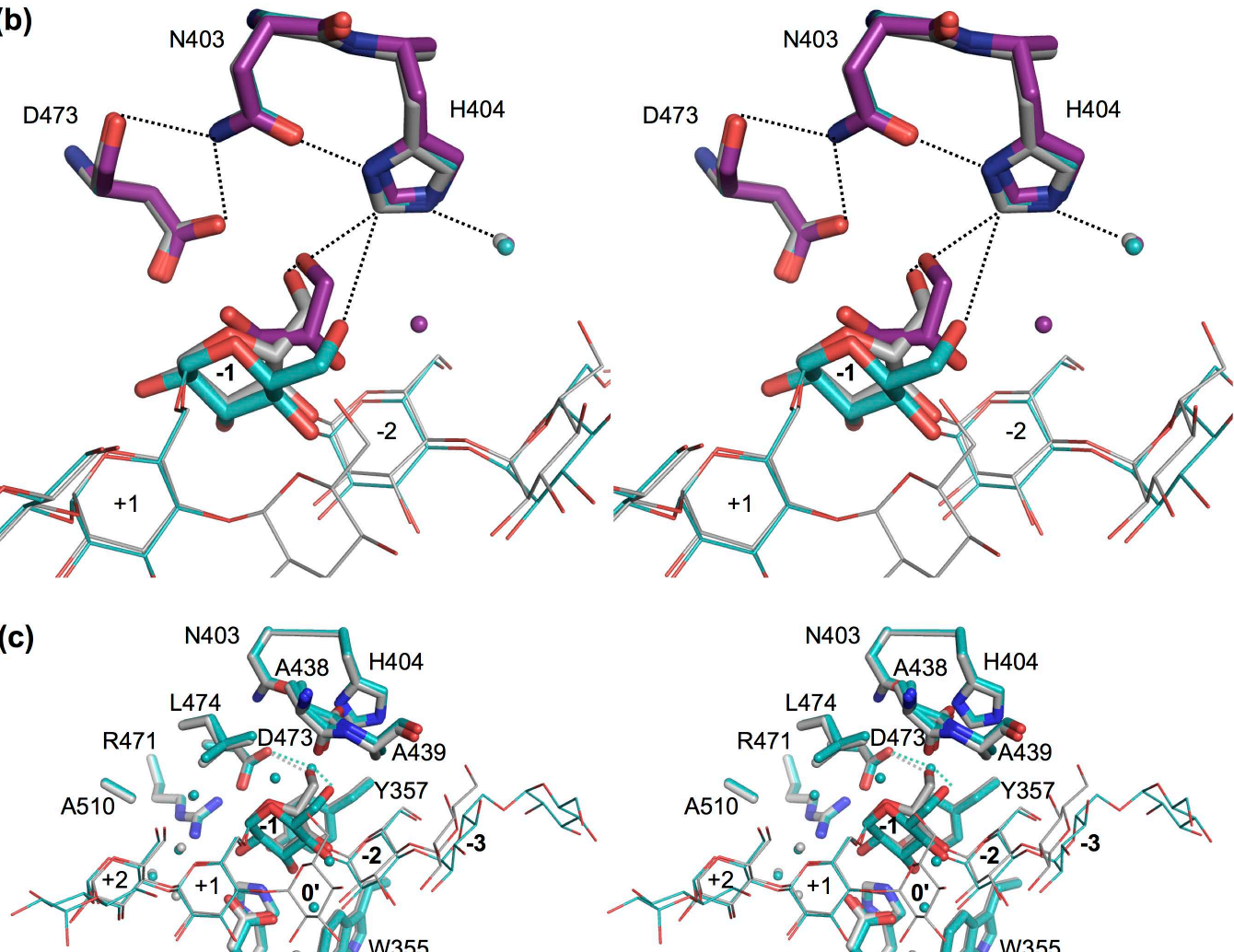

D642 H641 W355

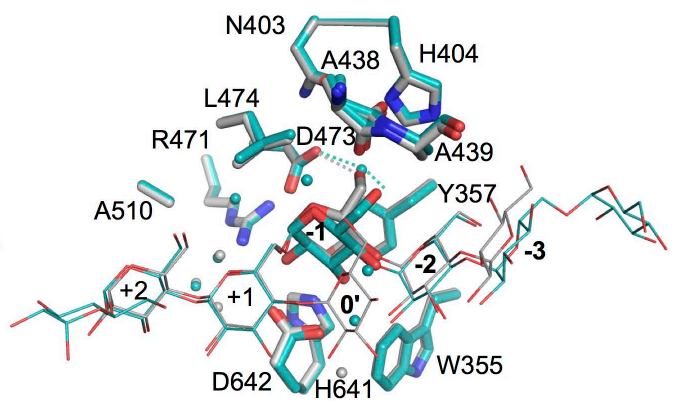

D642 16410 w355 
Fig. 5

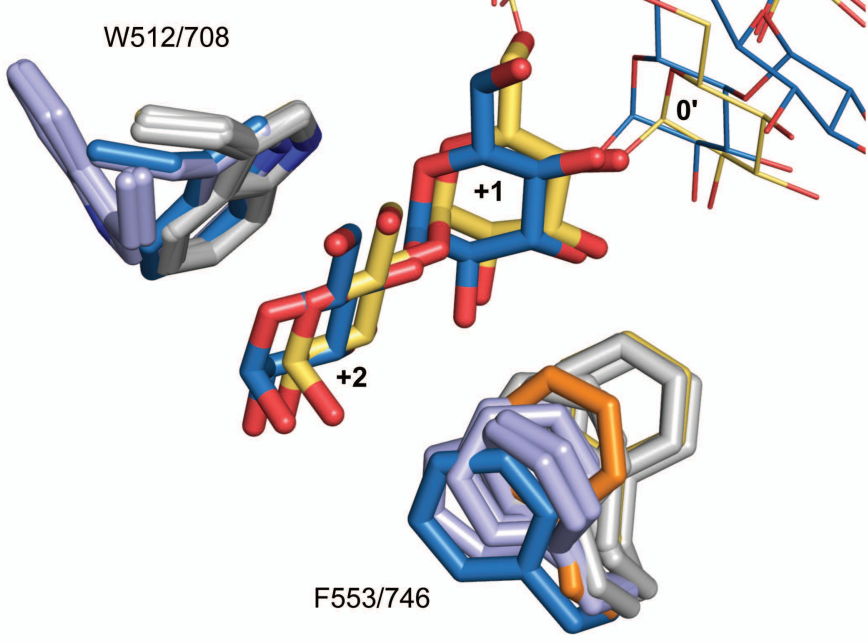




\section{Supplementary data for:}

"Oligosaccharide and substrate binding in the active site of the starch debranching enzyme barley limit dextrinase"

Marie S. Møller, ${ }^{\mathrm{a}, \mathrm{b}}$, Michael S. Windahl ${ }^{\mathrm{a}}$, Lyann $\mathrm{Sim}^{\mathrm{a}}$, Marie Bøjstrup ${ }^{\mathrm{a}}$, Maher Abou Hachem ${ }^{\mathrm{b}}$, Ole Hindsgaul $^{\mathrm{a}}$, Monica Palcic ${ }^{\mathrm{a}}$, Birte Svensson ${ }^{\mathrm{b}}$, Anette Henriksen ${ }^{\mathrm{a}}$

${ }^{\mathrm{a} C a r l s b e r g}$ Laboratory, Gamle Carlsberg Vej 10, DK-1799 Copenhagen V, Denmark; ${ }^{\mathrm{b}}$ Technical University of Denmark, Anker Engelunds Vej 1, Building 101A, DK-2800 Kgs. Lyngby, Denmark.

Supplemental Table S1-S2

Supplemental Figures S1-S8

Supplemental Video

Supplemental References 


\section{Table S1}

List of intermolecular interactions between $H v \mathrm{LD}$ active site residues and bound substrate or hydrolysis product, and intramolecular interactions between Glc units. Potential hydrogen bond interactions (interaction distances of less than $3.8 \AA$ ) are indicated with a bond length between donor and acceptor atoms.

\begin{tabular}{|c|c|c|c|c|c|c|c|c|}
\hline Subsite & G3G & & $H \nu$ LD-E510A & H-bond $(\AA)$ & $\mathrm{GG}^{2} 3-\mathrm{C}$ & & $H v$ LD-E510A & H-bond $(\AA)$ \\
\hline \multirow{4}{*}{-3} & \multirow{4}{*}{ Glc901 } & $\mathrm{O} 2$ & Lys727 Nz & 2.7 & \multirow{4}{*}{ Glc902 } & $\mathrm{O} 2$ & Lys727 Nz & 2.7 \\
\hline & & $\mathrm{O} 4$ & Ala439 O & 3.1 & & & & \\
\hline & & & Met440 & & & & & \\
\hline & & & Tyr700 & & & & Tyr700 & \\
\hline \multirow{9}{*}{-2} & \multirow{9}{*}{ Glc902 } & $\mathrm{O} 2$ & Asp698 OD1 & 2.7 & \multirow{9}{*}{ Glc903 } & $\mathrm{O} 2$ & Asp698 OD1 & 2.6 \\
\hline & & $\mathrm{O} 2$ & Asp642 OD1 & 3.8 & & $\mathrm{O} 2$ & Asp642 OD2 & 3.7 \\
\hline & & $\mathrm{O} 3$ & Asp698 OD2 & 2.6 & & $\mathrm{O} 3$ & Asp698 OD2 & 2.6 \\
\hline & & O6 & Asn358 OD1 & 2.6 & & O6 & Asn358 OD1 & 2.6 \\
\hline & & & Glc905 & & & & & \\
\hline & & & Trp355 & & & & Trp355 & \\
\hline & & & Tyr357 & & & & Tyr357 & \\
\hline & & & Tyr700 & & & & Tyr700 & \\
\hline & & & Lys727 & & & & & \\
\hline \multirow{13}{*}{-1} & \multirow{13}{*}{ Glc903 } & $\mathrm{O} 2$ & Asp642 OD2 & 2.6 & & $\mathrm{O} 2$ & Asp642 OD2 & 2.7 \\
\hline & & $\mathrm{O} 3$ & Asp642 OD1 & 2.8 & & $\mathrm{O} 3$ & Asp642 OD1 & 3.0 \\
\hline & & O6 & Asp473 OD2 & 2.7 & & O6 & Ala438 O & 3.1 \\
\hline & & $\mathrm{O} 2$ & Arg471 NH2 & 3.2 & & $\mathrm{O} 2$ & Arg471 NH2 & 3.2 \\
\hline & & $\mathrm{O} 2$ & His641 NE2 & 3.1 & & $\mathrm{O} 2$ & His641 NE2 & 3.2 \\
\hline & & $\mathrm{O} 3$ & His641 NE2 & 2.8 & & $\mathrm{O} 3$ & His641 NE2 & 2.9 \\
\hline & & O5 & Asp473 OD1 & 3.4 & Glc904 & O5 & Asp473 OD1 & 3.6 \\
\hline & & & Glc905 & & & & & \\
\hline & & & Trp355 & & & & Trp355 & \\
\hline & & & Tyr357 & & & & Tyr357 & \\
\hline & & & His494 & & & & & \\
\hline & & & Ala438 & & & & Ala439 & \\
\hline & & & Leu474 & & & & Leu474 & \\
\hline \multirow{10}{*}{$0^{\prime}$} & \multirow{10}{*}{ Glc905 } & $\mathrm{O} 2$ & Arg697 NH2 & 2.7 & & & & \\
\hline & & $\mathrm{O} 2$ & Arg697 NH1 & 3.9 & & & & \\
\hline & & $\mathrm{O} 3$ & Arg697 NH1 & 3.0 & & & & \\
\hline & & $\mathrm{O} 3$ & Lys727 NZ & 3.1 & & & & \\
\hline & & $\mathrm{O} 4$ & Lys727 NZ & 3.5 & & & & \\
\hline & & O6 & Ala438 O & 3.2 & & & & \\
\hline & & & Glc902 & & & & & \\
\hline & & & Glc903 & & & & & \\
\hline & & & Asp698 & & & & & \\
\hline & & & Arg697 & & & & & \\
\hline \multirow{8}{*}{+1} & \multirow{8}{*}{ Glc904 } & $\mathrm{O} 2$ & Asn643 ND2 & 2.8 & & $\mathrm{O} 2$ & Asn643 ND2 & 2.8 \\
\hline & & $\mathrm{O} 3$ & Asn643 ND2 & 3.2 & & $\mathrm{O} 3$ & Asn643 ND2 & 3.4 \\
\hline & & $\mathrm{O} 3$ & Asn643 OD1 & 3.0 & & $\mathrm{O} 3$ & Asn643 OD1 & 2.9 \\
\hline & & $\mathrm{O} 3$ & Arg697 NH2 & 3.7 & Glc005 & & & \\
\hline & & & Trp512 & & Sit & & Trp512 & \\
\hline & & & Asp642 & & & & Asp642 & \\
\hline & & & Phe553 & & & & & \\
\hline & & & Leu474 & & & & & \\
\hline \multirow{7}{*}{+2} & \multirow{8}{*}{ Glc906 } & $\mathrm{O} 2$ & Asp541 OD2 & 3.1 & \multirow{7}{*}{ Glc906 } & \multirow[t]{2}{*}{$\mathrm{O} 2$} & \multirow[t]{2}{*}{ Asp541 OD2 } & \multirow[t]{2}{*}{2.9} \\
\hline & & $\mathrm{O} 2$ & Asn551 OD1 & 3.8 & & & & \\
\hline & & $\mathrm{O} 2$ & Arg544 NH2 & 2.9 & & $\mathrm{O} 2$ & Arg544 NH2 & 3.0 \\
\hline & & $\mathrm{O} 3$ & Arg544 NH1 & 2.8 & & $\mathrm{O} 3$ & Arg544 NH1 & 2.8 \\
\hline & & & Trp512 & & & & $\operatorname{Trp5} 12$ & \\
\hline & & & Phe514 & & & & Phe514 & \\
\hline & & & Phe553 & & & & Phe553 & \\
\hline+3 & & & & & Glc907 & & Phe553 & \\
\hline
\end{tabular}




\section{Table S2}

Cremer-Pople ring puckering parameters observed for the $\alpha$-D-glucose units in the -1 subsite in the crystallized LD complexes

\begin{tabular}{|c|c|c|}
\hline Ligand & $\theta\left({ }^{\circ}\right)^{\mathrm{a}}$ & $\mathbf{Q}^{\mathbf{b}}$ \\
\hline $\mathrm{G} 4(25 \mathrm{mM})$ & No $G$ in subsite -1 & No $G$ in subsite -1 \\
\hline G4 (300mM) & No $G$ in subsite -1 & No $G$ in subsite -1 \\
\hline G2ßSCD & No $G$ in subsite -1 & No $G$ in subsite -1 \\
\hline $\mathrm{G} 2 \mathrm{SG}^{2} 4$ & 32.250 & 0.519 \\
\hline $\mathrm{G}^{3} \mathrm{G}^{1} 3$ & 25.941 & 0.582 \\
\hline $\mathrm{GG}^{2} 3-\mathrm{G}^{2} 3$ & 3.937 & 0.630 \\
\hline
\end{tabular}

${ }^{\mathrm{a}} \theta\left(^{\circ}\right)=0$ for a ${ }^{4} \mathrm{C}_{1}$ chair conformation

${ }^{\mathrm{b}} \mathrm{Q}=0$ for a flat six-membered ring

\section{Reference}

D. Cremer \& J. A. Pople: A General Definition of Ring Puckering Coordinates. J. Am. Chem. Soc. 97, 1354508 (1975) 


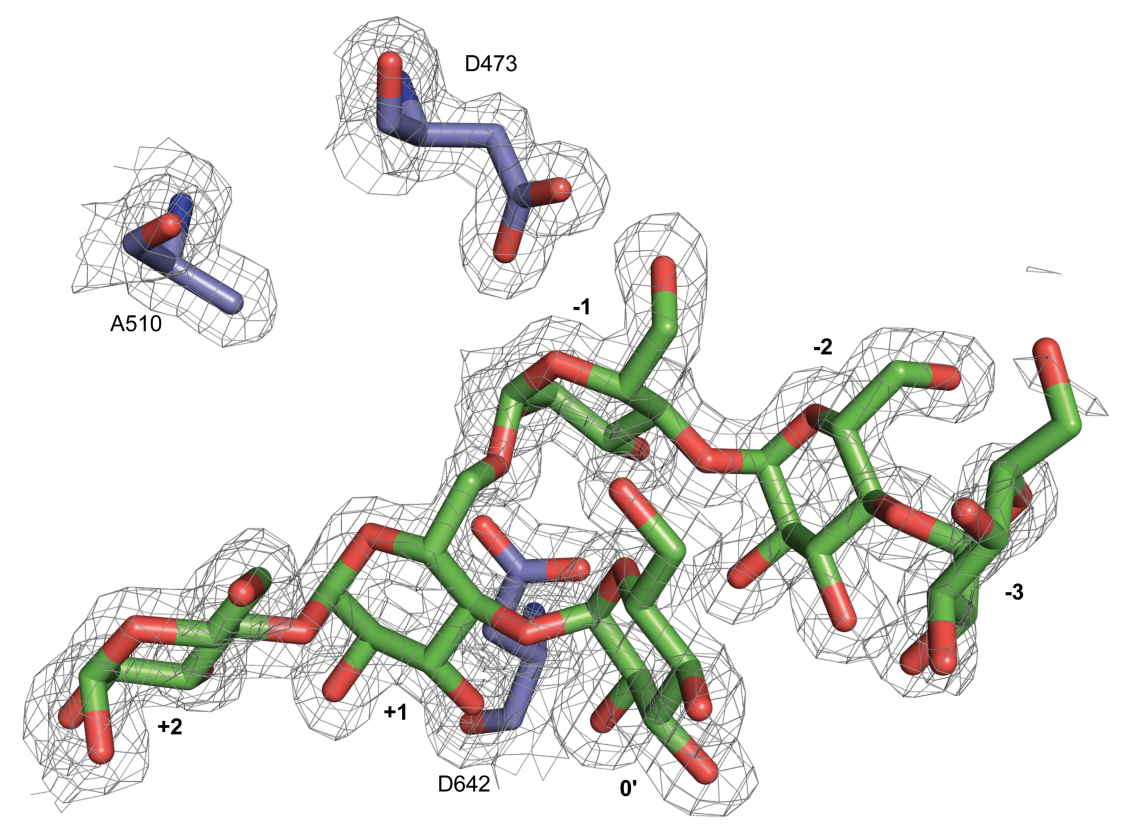

B

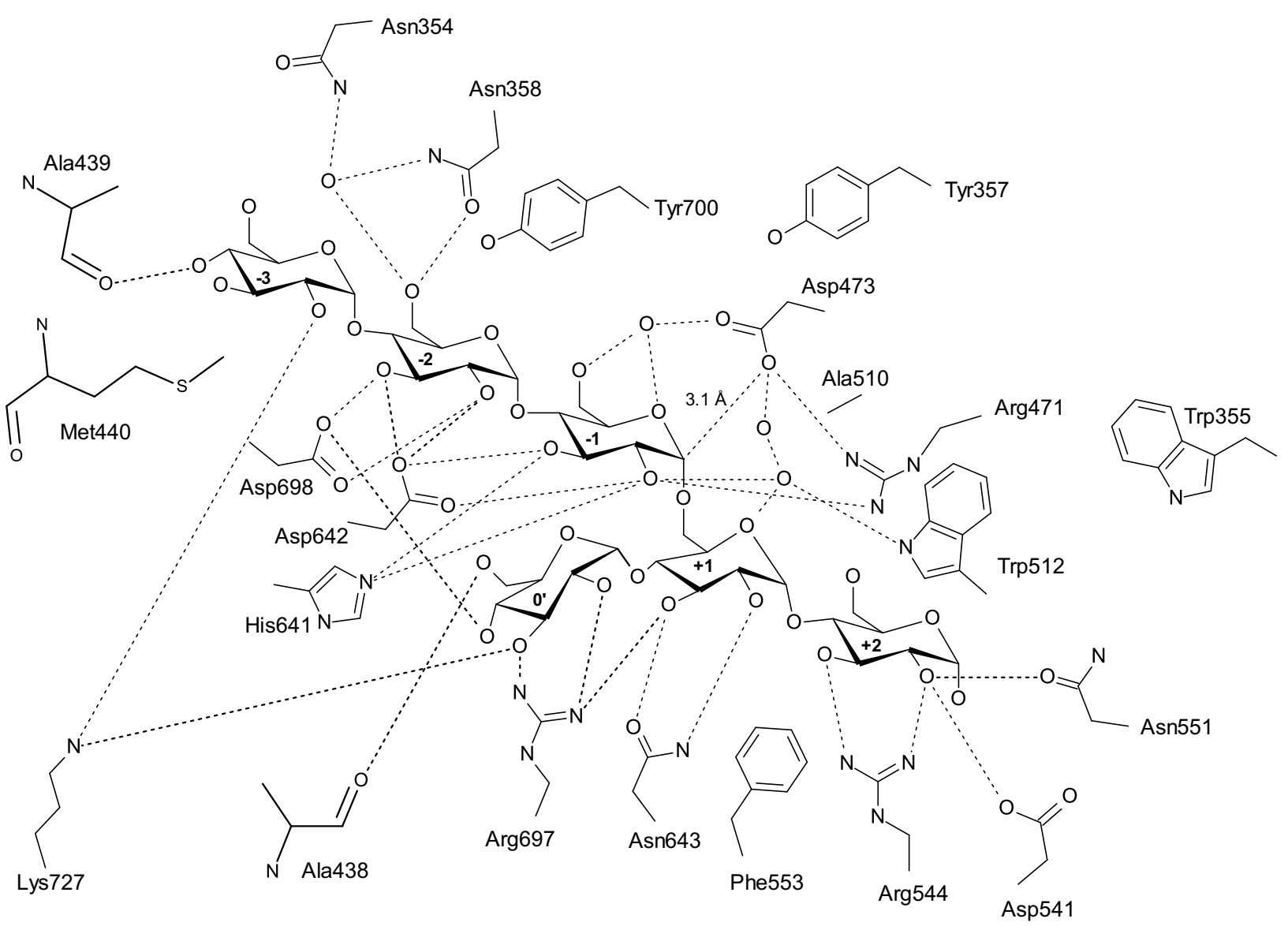

Figure S1. (A) 1.0 $\sigma$ sigmaA weighted $2 \mathrm{Fo}-\mathrm{Fc}$ electron density map surrounding the G3-G'3 molecule from the $H v \mathrm{LD}-\mathrm{E} 510 \mathrm{~A}-\mathrm{G} 3-\mathrm{G} 3 \mathrm{c}$ complex. (B) Binding of the $H \nu \mathrm{LD}$ substrate G3-G'3 in the inactive $H v \mathrm{LD}-$ E510A variant. Dotted lines illustrate hydrogen bonds. The Glc units are numbered according to the binding subsites they occupy. For the sake of clarity, not all van der Waals interactions listed in Table S1 have been included. 


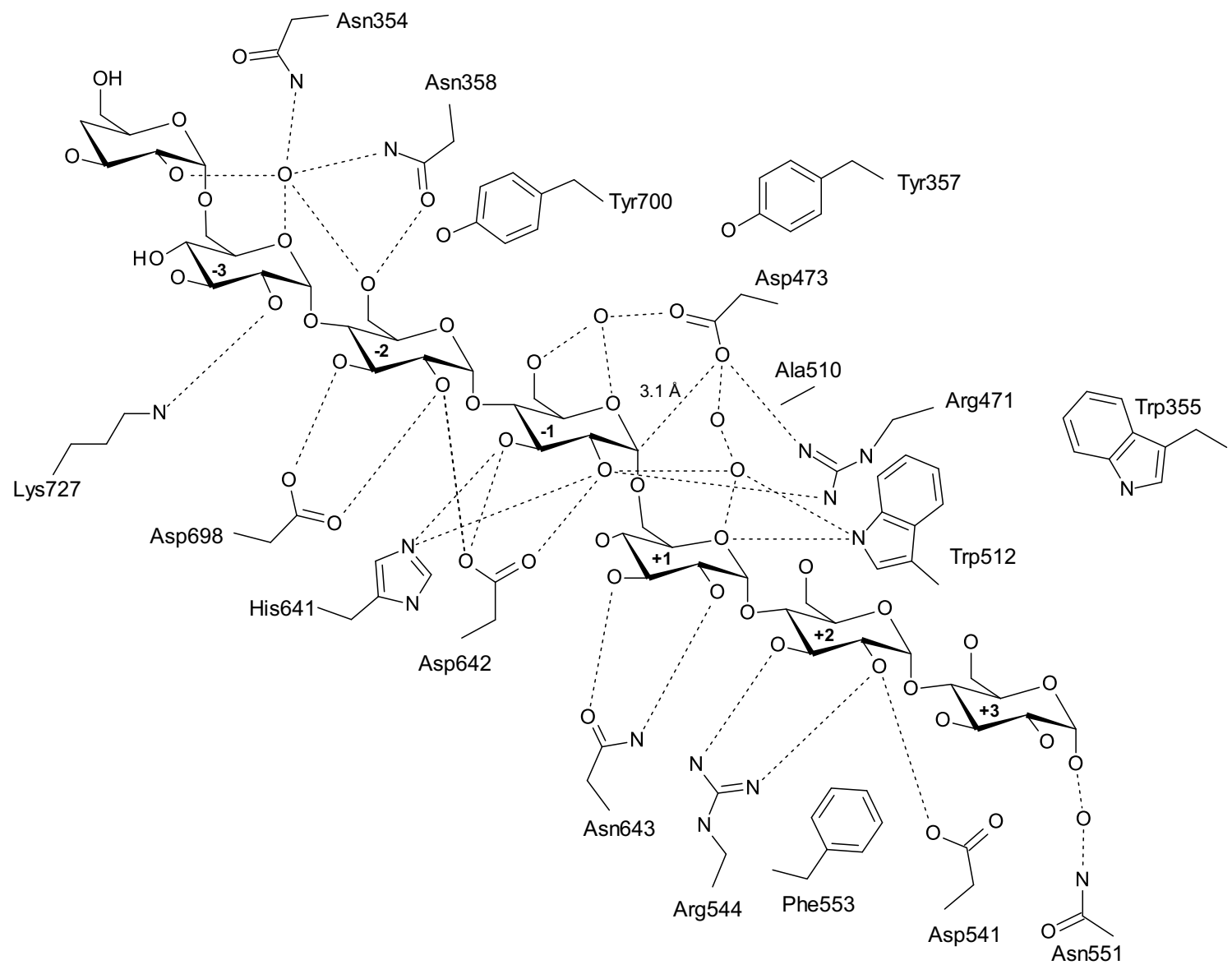

Figure S2. Binding of the $H v \mathrm{LD}$ substrate G-G' $3-\mathrm{G}$ ' 3 in the inactive $H v \mathrm{LD}-\mathrm{E} 510 \mathrm{~A}$ variant. Dotted lines illustrate hydrogen bonds. The Glc units are numbered according to the binding subsites they occupy. For the sake of clarity, not all van der Waals interactions listed in Table S1 have been included. 
A

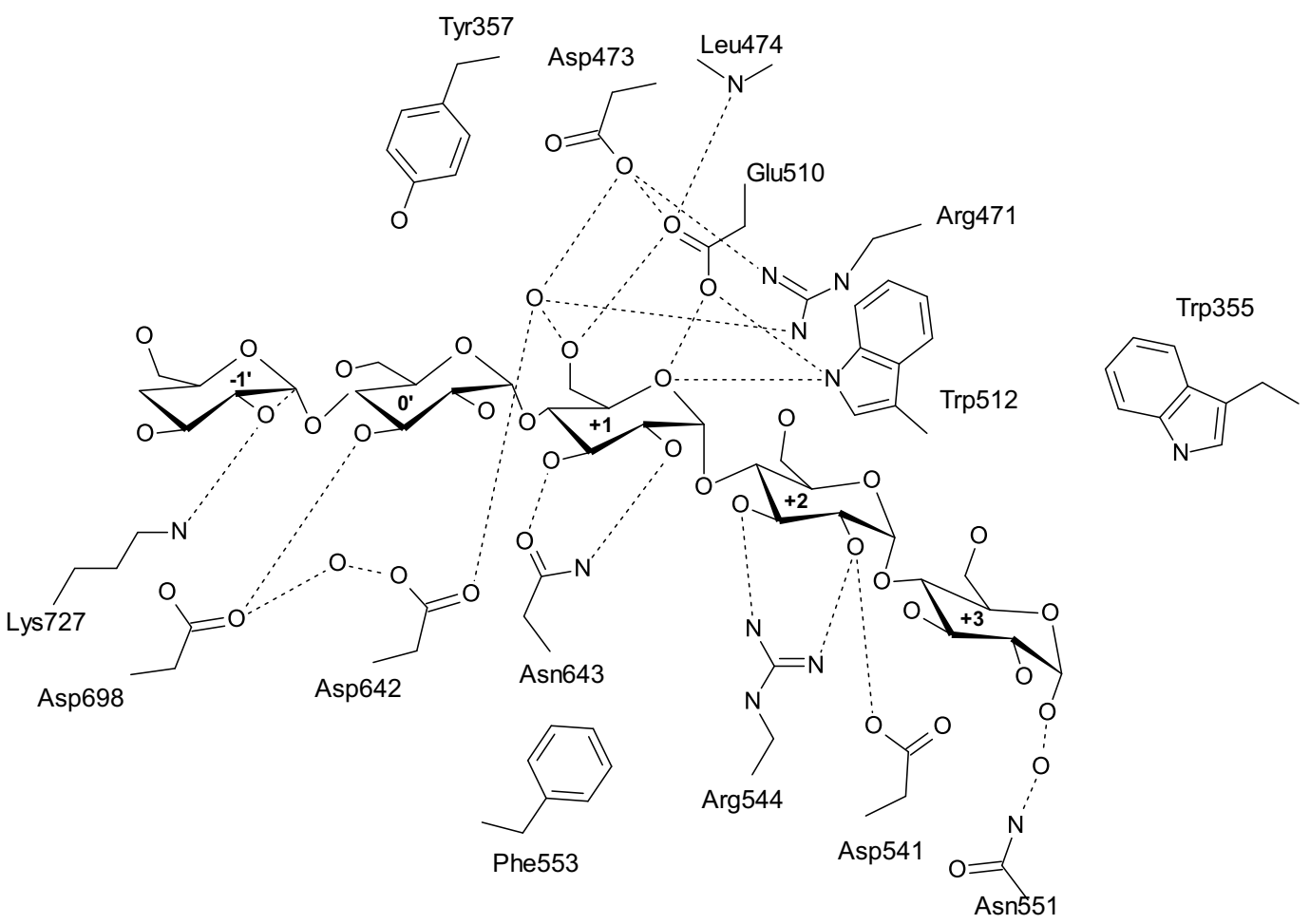

B

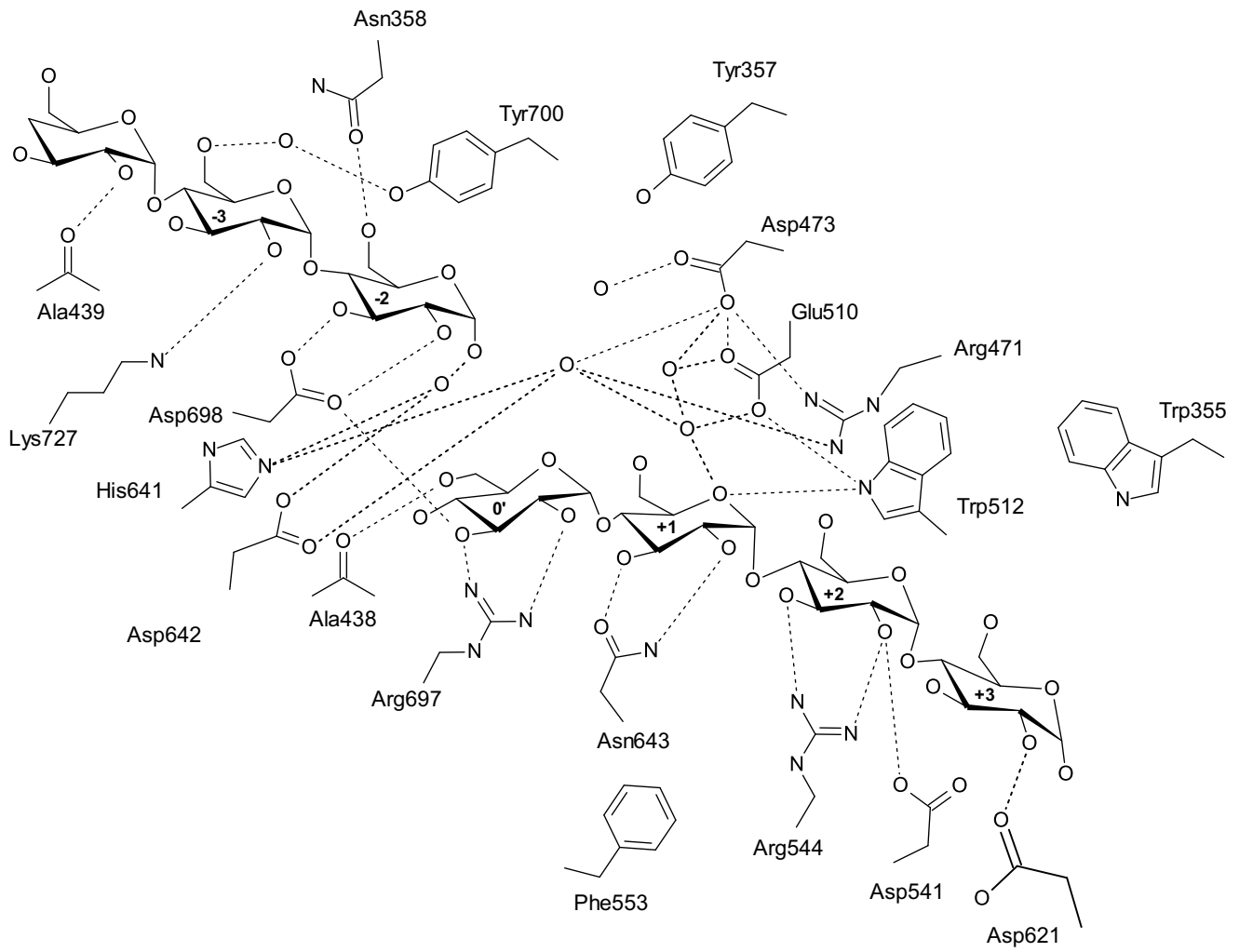

Figure S3 Binding of $\mathrm{G} 4$ in the $H v \mathrm{LD}$ active site. (a) Active site of $H v \mathrm{LD}$ obtained by co-crystallization with a mixture of $25 \mathrm{mM} \mathrm{G} 3$ and $25 \mathrm{mM} \mathrm{G} 4$. Two partly superposed G4 molecules occupied subsites -1' to +3. (b) Active site of $H v \mathrm{LD}$ obtained by soaking the $H v \mathrm{LD}$ crystals with $300 \mathrm{mM}$ G4. Dotted lines illustrate hydrogen bonds. The Glc units are numbered according to the binding subsites they occupy. 

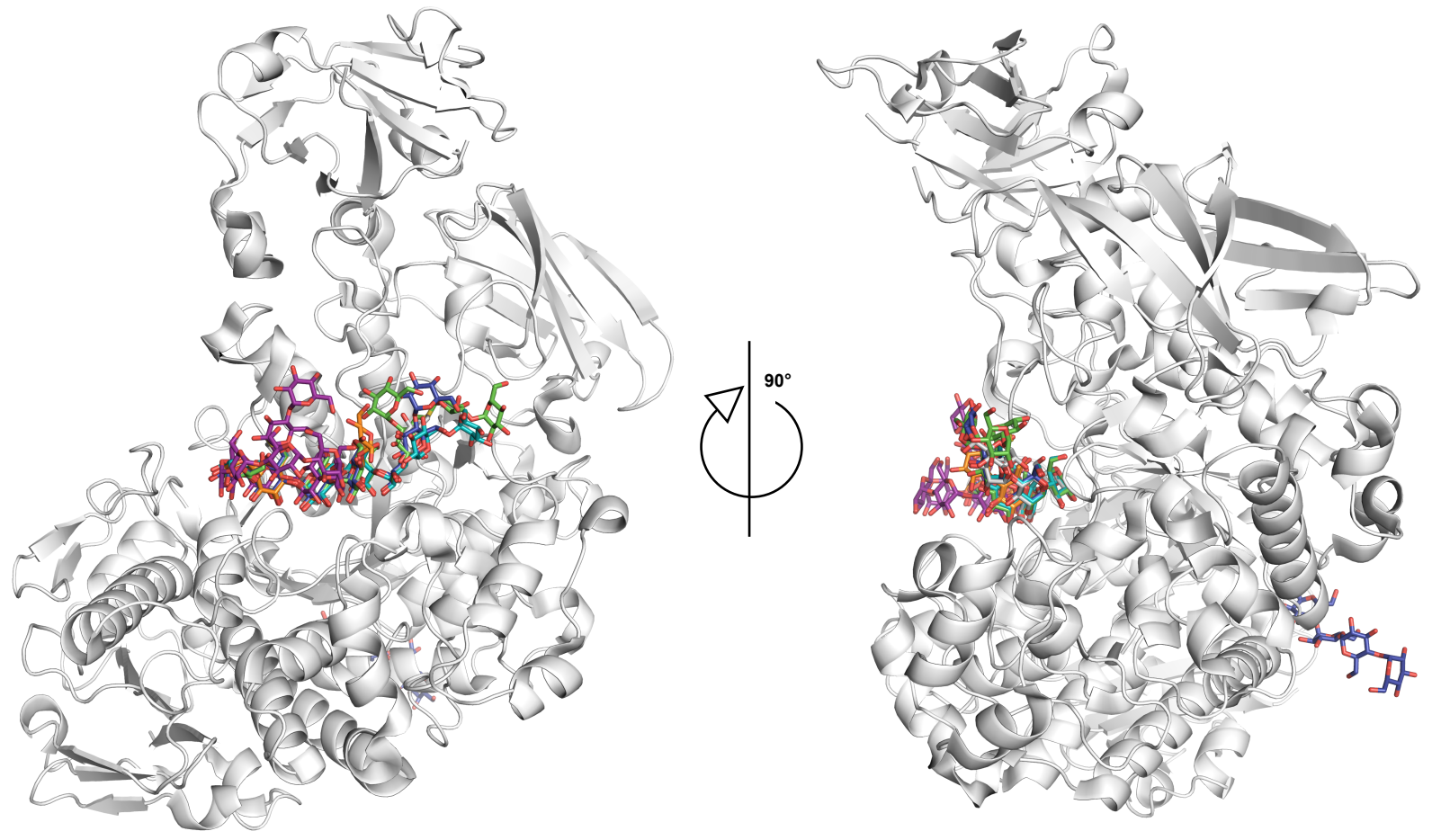

Figure S4. Overall structure of $H v \mathrm{LD}$ with ligand structures from this study superimposed (grey sticks, $H \nu \mathrm{LD}-\mathrm{E} 510 \mathrm{~A}-\mathrm{G} 3 \mathrm{G}^{1} 3$; turquoise sticks, $H \nu \mathrm{LD}-\mathrm{E} 510 \mathrm{~A}-\mathrm{GG}^{2} 3 \mathrm{G}^{2} 3$; purple sticks, $H v \mathrm{LD}-\mathrm{G} 4$ (300 mM); orange sticks, $H \nu \mathrm{LD}-\mathrm{G} 4(25 \mathrm{mM})$; magenta sticks, $H \nu \mathrm{LD}-\mathrm{G} 2 \mathrm{~S} \beta \mathrm{CD}$, green sticks, $\left.H \nu \mathrm{LD}-\mathrm{G} 2 \mathrm{SG}^{2} 4\right)$. The secondary interaction site observed in the $H v \mathrm{LD}-\mathrm{G} 4(300 \mathrm{mM})$ structure can be seen when the structure is rotated $90^{\circ}$ about its vertical axis (top right panel). 


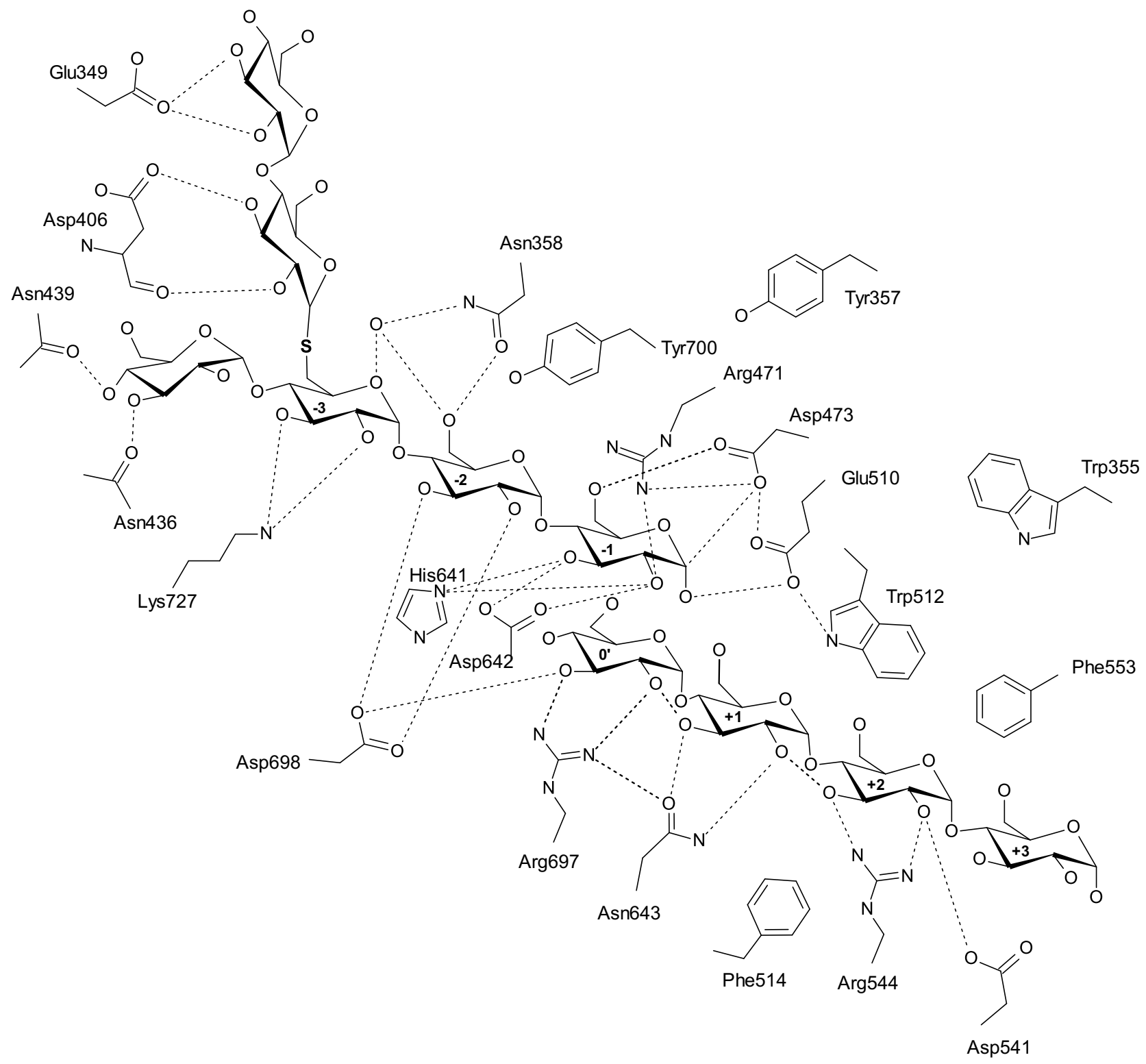

Figure S5. Binding of G2S-G" 4 in the $H v$ LD active site. Dotted lines illustrate hydrogen bonds. The Glc units are numbered according to the binding subsites they occupy. 


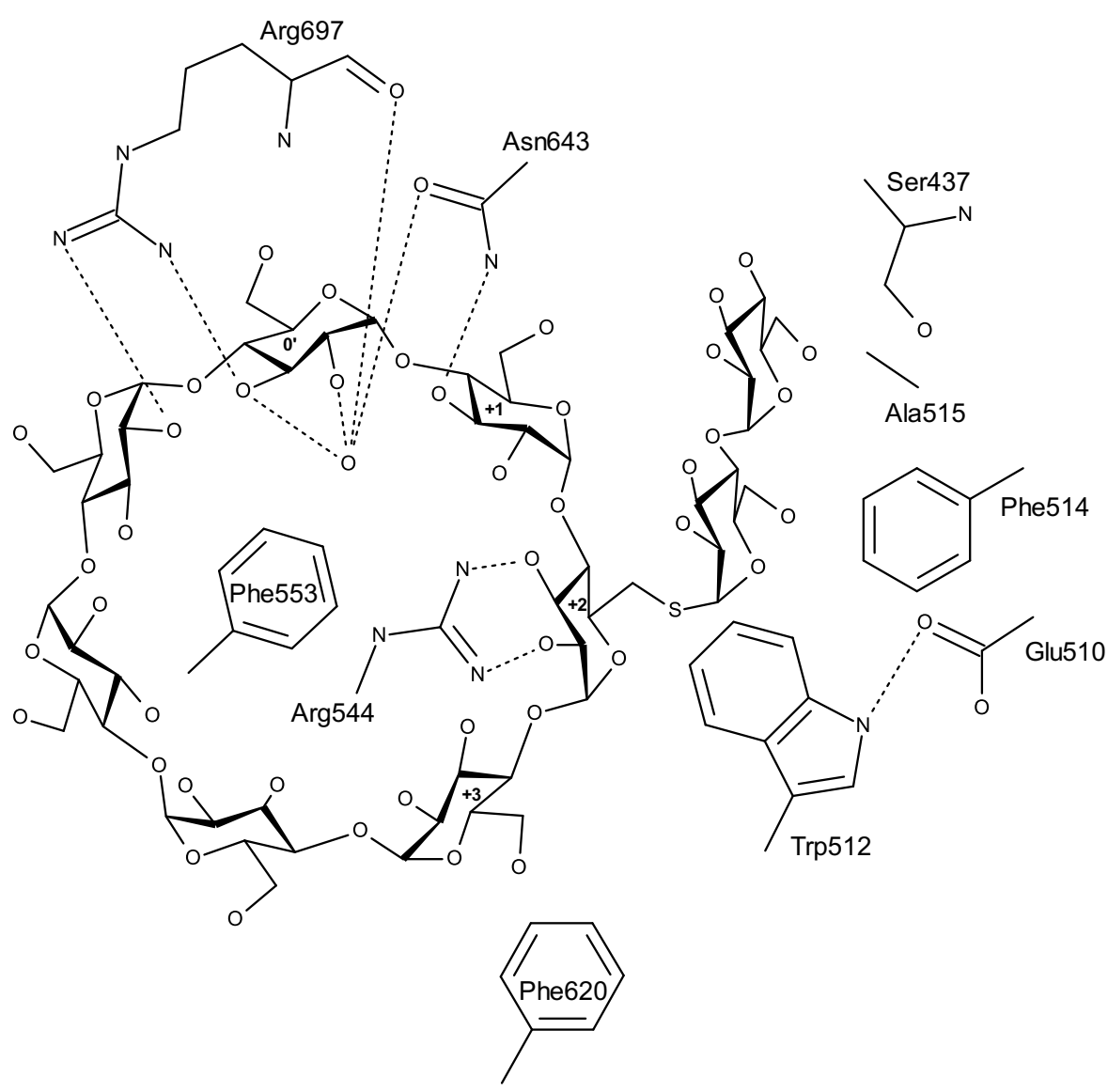

Figure S6. Binding of G2S- $\beta C D$ in the $H \nu \mathrm{LD}$ active site. Dotted lines illustrate hydrogen bonds. The Glc units are numbered according to the binding subsites they occupy. 
Conservation:

gi_11320925_gb_AAG33958. gi_42712988_gb_AAS36537. gi_77173560_gb_EA076676. gi $209541307 \mathrm{gb}$ ACI61883. gi 251820781 emb CAR4754 gi_3411266_gb_AĀ̄11599.1 gi_23330127_gb_AAN2 6412. gi_119633045_gb_ABL84490. gi 27311611_gb AA000771. gi $3172048 \mathrm{dbj}$ BAA28632.1 gi $1610856 \overline{8} 5 \mathrm{dbj}$ BAF9390 gi $5969549 \mathrm{gb}$ AAE10887.1 gi_29338971_gb_AA076770. gi $34606150 \mathrm{gb}$ AAQ80298. gi 68271034_gb_AAY89038, gi 666867 gb AAB06264. gi $483621 \overline{5} \mathrm{~g} \bar{b}$ AAD30387.1 gi_56381204_dbj_BAD77112. gi_23476935_emb_CAC85704.

GH13_14 gi 37788269 gb AAP45012. gi 228654 prf $1808262 \mathrm{~A}$ gi_228654_pr_-1808262A g1_-101063635_gb_ARPO9962. gi_401063639_gb_AFP89964. gi_401063637_gb_AFP89963. gi_4982428_gb_ĀAD36907.1 gi 224579361_gb_ACN58254. gi $3089609 \mathrm{gb}$ ĀA 15073.1 gi $1486106 \overline{7} \mathrm{db} j$ BAB 62095 .

GH13_12

3faw_chainA_p00 2yaO_chainA_p002

4 aio chainA p003

GH13_13

$2 \mathrm{fgz}$ chainA poo

2yoc_chaina_po

recha

2e8y_chainA_p006
2wan chainA_p007

3 wdh chainA p008

Consensus aa:

Consensus ss:

Conservation:

gi_11320925 gb AAG33958.1 gi_42712988_gb_AAS36537. gi 77173560 gb EA076676.1 gi ${ }^{-} 20954130 \overline{7} \mathrm{~g} \overline{\mathrm{b}}$ ACI 61883 gi 251820781 emb CAR47543 gi_3411266_gb_AĀ 11599.1 gi $2333012 \overline{7} \mathrm{gb}$ AAN2 6412 .

GH13_13 . gi 27311611 gb AA000771.1 gi 3172048 dbj BAA28632.1 gi_161085685_dbj_BAF93906 gi_5969549_gb_AAE'10887.1 gi_29338971_gb_AA076770. gi 34606150 gb AAQ80298.1 gi $68271034 \mathrm{gb}$ AAY89038. gi $666867 \mathrm{~g} \overline{\mathrm{b}}$ A. $\bar{A} B 06264.1$ gi_4836215_gb_AAD30387.1 gi_56381204_dbjj_BAD77112. gi-23476935 emb CAC85704.

GH13_14 gi 44662948 gb AAS47565. gi $37788269 \mathrm{gb}$ AAP 45012 . gi_228654_prf_1808262A_t gi_401063635_gb_AFP8996 gi 401063639 gb AFP89964. gi_401063637_gb_AFP89963.

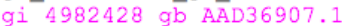
gi_224579361_ḡb_ACN58254. gi_3089609_gb_AĀC15073.1 gi_14861067)dbj_BAB62095. 3 faw chain ${ }^{-}$p 001

GH13_12 2yao_chainA_p002 4 aio chainA p003 2 fgz chain A p004 2 yoc chainA p005 2yoc_chainA_p005 2wan_chainA_p007 3wdh chaina p008 Consensus aa: Consensus ss:
$6 \quad 65955897$

8755

STPAIAKDLTKPFGTFEAFIE作

DAVIYEAHVRDFTSDQSLDGKLKNQLGTFAAFSE--

QDAI YEAHVRDFTSDKALEGKLTHPFGTFSAFVE--

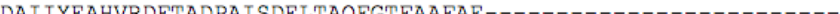

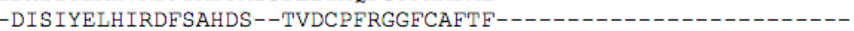

-DISLYELHIRDFSAYDL--TVHPDIRGGYLAFS--

-DITIYELHIRDFSAHDG--TVDSDSCGGFRAFAY--

-DISIYELHVRDFSANDE--TVEPENRGGYLAFTS-

DIYELHIRDESAHDS- -TVDCNSRGGFVHLHFRLFRLNLINDECSPPITKHPGRIME DAIVDELHIRDETSSSTS-GVSAGNRGKEIGVIO-------

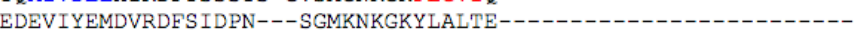
-DMIIYEMHHRDFSVDST---SGVKNKGKYLALTE-

EDEVIYEMDVRDFS IDSN---SGMKNKGKYLALTE--

-TDAI ITEANVRDMTINPNS-GVSEANRGKYLGFVE---

-DAI I YEMHVRDFTIDQSS-GIGENLRGKFLGFCQ

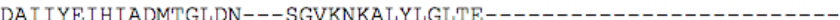

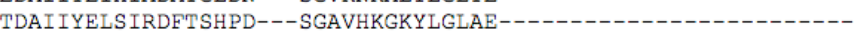

TDAI IYELS IRDFTSHPD---SGAVHKGKYLGLAE-

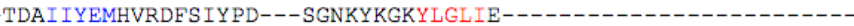

-TDAI I YEMHVRDFS IYPQ---SGNKYKGKYLGLIE---

DAVIYTMHRDETIHPE-- SGVTHKCKYICITTE---1

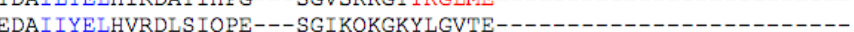

EDAI IYELHVRDLS IQPE---SGIKQKGKYLGVTE--

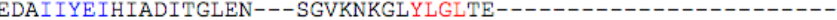

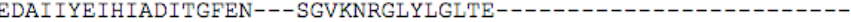

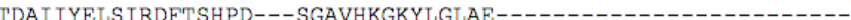

TDAI I YELS IRDFT SHPD---SGAVHKGKYLGLAE----------------------

QDAVIYEAHVRDFT SDQSLDGKLKNQLGT FAAFSE---

DEKPKLDSESDITIYELHIRDFSAHDG--TVDSDSRGGFRAFAY

- - ADEKPKLDSFSDITI YELHIRDFSAHDG--TVDSDSRGGFRAFAY WDNLTMPHAOKTKADIAKMTIHESHIRDLSAWDO--TVPAELRGKYLALTA-DPAGWQGDHEQTPANPVDEVIYEAHVRDFSIDAN---SGMKNKGKYLAFTE--AKTNI PKPSMSLF I SMTDAI I YEMHIRDFT IHHE---SGVRQKGKYVGLTE

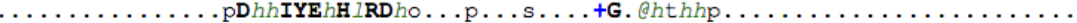
eeeee $\begin{array}{lllll}6 & 5 & 5958665669 & 5 & 77\end{array}$ KLDYLKDLGVTHIQLLPVLSYYFVNELKN-HEHI -KLDYIQELGVTHIQLLPVMSYYFSNEFES-GERM OLDYIKDLGVTHVQLLPVISYEYANELD--KTRS-

RLSYLKELGVTHIOLLPVMSYYFVNELKN-AERM-

-QDSA-----GVNHLEKLSAAGLTHVHLLPSFOFAEVDDDKKKWKFV--

-OASA------GMOHLRKLSDAGLTHVHLLPSFHFAGVDDIKSNWKFV-

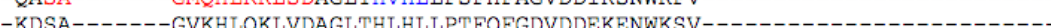
DDA

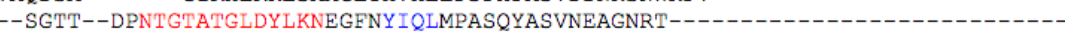
-KGTK---GPDNVKTGIDSLKQLGITHVQLMPVEASNSVDET---

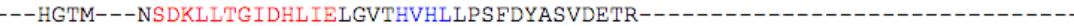

--KGTK---GPDNVKTGVDSLKQLGITHVQLQPVFAFNSVNEN- -

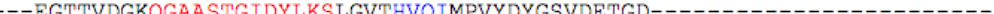

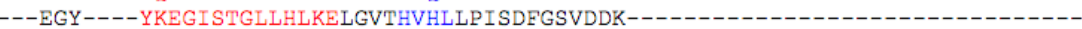

---KGTR---GPNGVTTGLDHLVELGVTHVHI LPMFD FWTGDEADK--

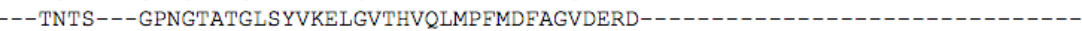

--TNTS---GPNGTATGLSYVKELGVTHVQLMPFMDFAGVDERD-

---KGIT---GPGGVKTGLDHLVELGITHIHLLPTY DFAS IDDS---

--KGTM---GPGGVKTGIDHLVELGITHIHLLPTYDFASIDDS--

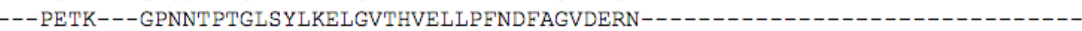

-EGTT---GRNGTLTGLSHI KDLGVTHVELLPLYCFGGVDEAN-

-KGTR---GPEGVKTGLDHMKDLGVTHVQLLPI FDYASVNEENV--

-ENTK---GPGCVTMCISHLVELGVTHVHTLPEFDYTGDEIDK--

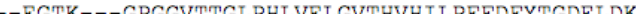

---TNTS---GPNGTATGLSYVKELGVTHVQLMPFMDFAGVDERD---TNTS---GPNGTATGLSYVKELGVTHVQLMPFMDFAGVDERD-

-KLDYLKDLGVTHIOLLPVLSYYFVNELKN-HERI

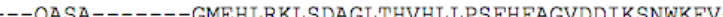

DESTQ ---GDSN------MVQHLKTLSASGVTHVELLPVFDLATVNEFSDKVADIQQPFSRLCEVNSAVKSSEFAGYCDS ---TDTQ---TANGSSSGLAYVKELGVTHVELLPVNDFAGVDEEK--1-1-10 -- HGTK---GPDHVKTGIDSLKELGITTVQLQPVEE FNS IDET

---RGTT---GPNGTLTGLSYIKQLGVTHVQLMPVQDFEGVDELQ--

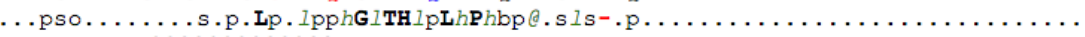
hhhhhhhhhhhhh
(Figure is continued on the following pages) 
GH13_12 AAG33958.1. gi-77173560_gb_AAS36537. gi_209541307]_g $\bar{b}$ ACI 61883 gi_251820781_emb_CAR47543 gi 3411266 gb AAD11599.1

GH13_13 gi $2333012 \overline{7} \mathrm{gb}$ AAN gi $11963304 \overline{5} \mathrm{gb}$ ABL84490. gi 27311611 gb ÂA000771.1 dbj BAA28632.1 1_161085685 dbj_BAF93906 gi 5969549_gb_AAE10887.1 gi $2933897 \overline{1}$ gb AA076770.1 gi $34606150 \mathrm{gb}$ AAQ80298.1 gi_68271034_gb_AAY89038. gi_666867_gb_AĀA06264. gi_4836215_gb_AAD30387.1 gi_56381204_dbj_BAD77112. gi_23476935_emb_CAC85704.

GH13_14 gi_44662948_gb_ĀAS47565. gi_37788269_gb_AAP45012.1 gi_228654_prf_1808262A gi 401063635 gb AFP89962. gi 401063639 gb AFP89964. gi $401063637 \mathrm{gb}$ AFP89963. gi_4982428_gb_ĀĀD36907.1 gi_224579361_ḡb_ACN58254. gi $3089609 \mathrm{~g} \bar{b}$ AĀC15073.1

GH13_12 gi $14861067 \mathrm{db} j$ BAB62095. 3faw chainA p001 2yaO_chainA_p002 4 aio chainA p003 2fgz_chainA_p004

GH13_13 2 yoc chainA p005 2 e8y chainA p00 2wan_chainA_p007

GH13_14 3 wdh chainA pO
Consensus aa: Consensus ss:

Conservation:

GH13_12 gi $11320925 \mathrm{gb}$ AAG33958. gi_42712988_gb_AAS36537. gi_77173560_gb_EA076676.1 gi_209541307_gb_ACI 61883 . gi_251820781_emb_CAR47543 gi $3411266 \mathrm{gb}$ AAD11599.1 gi $2333012 \overline{7} \mathrm{gb}$ AAN2 $6412 . \overline{1}$ gi $11963304 \overline{5} \mathrm{gb}$ ABL84490. gi 27311611 gb AAO00771.1 gi_3172048_dbj_BAA28632.1 gi_161085685_dbj_BAF93906 gi 5969549 gb AAE 10887.1 gi_29338971_gb_AA076770, gi_34606150_gb_AAQ80298.1 gi-68271034 gb AAY89038.1 gi $483621 \overline{5} \mathrm{gb}$ AAD30387. gi $56381204 \mathrm{db} j$ BAD77112. gi 23476935 emb_CAC85704. gi-44662948-gb AAS47565.1 gi 37788269-gb_AAP45012.1 gi_228654_prf_1808262A gi 401063635 gb AFP89962. gi 401063639 gb AFP89964. gi_401063637_gb_AFP89963. gi_4982428_gb_ĀAD36907.1 gi_224579361_gb_ACN58254. gi 3089609 gb AAC15073.1

gi 14861067 dbj

GH13_12

3faw_chainA_p001

2yaO_chainA_p002

4 aio chainA p003

2fgz_chainA p004

2 yoc chaina p005

2e8y_chainA_p006

2wan_chainA_p007

3wdh_chainA_poo

Consensus aa:

Consensus ss:
SDY-----ASSNSNYNWGYDPONYESLTGMYSSDPKNPEKRIAEFKNLINEIHK-R

LEY-----ASTGTNYNWGYDPHNYFSLSGMYSENPEDPELRIKEFKNLINEIHK-R

TAY----- TSSDNNYNWGYDPOSYFALSGMYSEKPKDPSARIAELKOLIHDIHK-R

TAY-----TSSDNNYNWGYDPQHYFALSGMYSANPNDPALRIAELKNLVNEIHK-R SEY------ASSNSNYNWGYDPQSYFAFTGMYSTDPTDPMKRIEEFKNLVNEIHK- $Q$

-DEIELSKLPP----GSDLQQAAIVAIQEEDPYNWGYNPVVWGVPKGSYASNP-DGPSRI IEYRLMVOALNR-I -DTKRFETLPP----DSEEQQAQITAIRDEDGYNWGYNPVLWGTPKGSYATDP-NGPCRI IEFRKMVQALNR-I --DECKLATFPP----GSDMQQEAVVAIQEEDPYNWGYNPVLWGVPKGSYASDP-DGPSRI IEYRQMVQALNR-I --DT SLLEGLRP----DSTEAQARITEIQNDDGYNWGYNPVLWGVPKGSYASDP-TGPCRI IEFRKMVQALNC-T --DEAQLAKLPP----GSDEQQAAIVSIQQEDPYNWGYDPVLWGVPKGSYASNP-DGPSRI IEYRQMVQALNR-I

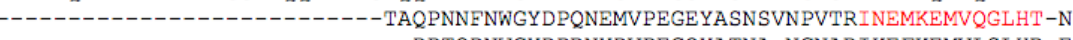
-DPTODNWGYDPRNYDVPEGQYATNA-NGNARIKEFKEMVLSLHR-LNENSYNWGYDPQNYNVPDGSYATDPYOPATRVKEFKOMVOALHK-A DPTQYNWGYDPRNYNVPEGQYATNA-NGTTRIKEFKEMVLSLHQ-D LSYGAQYNWGYDPENYNVPEGSYSSDPSDPSARVKEMKQMVSGLHK-N -NPDKRYNWGYDPVLYQCPEYWYSTKS-GGIEALKELRTMIKKLHE-N DFERSYNWGYDPYLFTVPEGRYSTDPINPYTRI IEVKQMVKALHE-N POAAYNWGYNPLHLYAPEGSYATDPADPYARIVELKOAIHTLHE-N POAAYNWGYNPLHLYAPEGSYATDPADPYARIVELKOAIHTLHE-N RDDQYNWGYDPRLYNVPQGTYSTNAADGLTRIREYKEMVMGLNK-A RDDQYNWGYDPRLYNVPQGTYSTNAADGLTRIREYKEMVMGLNR-A PLQQYNWGYNPLHYNAPEGSYATDPNDPYARIRELKRAIHTLQS-N PSSAYNWGYNPLYYNAPTGYYATNPSDPYNRIVECKQLIETEHE-H -NEPOYNWGYDPKNFNVPEGSYSTNPYEPTVRITELKOMVQTLHD-N NEPOYNWGYDPKNFNVPEGSYSTNPYEPTVRITELKOMIOTLHD-N -DFEKYYNWGYDPYLFMVPEGRYSTDPKNPHTRIREVKEMVKALHK-H DFEKYYNWGYDPYLFMVPEGRYSTDPRNPYARIREVKEMVKALHR-H PQAAYNWGYNPLHLYAPEGSYATDPADPYARIVELKQAIHTLHE-N POAAYNWGYNPLHLYAPEGSYATDPADPYARIVELKOAIHTLHE-N TAY SDY------ASSNSNYNWGYDPQNYFSLTGMYS SDPKN PEKRIAEFKNLINEIHK-R DECELATEPP----GSDMQQAAVVAIQEEDPYNWGYNPVLWGVPKGSYASDP-DGPSRI IEYRQMVQALNR-I

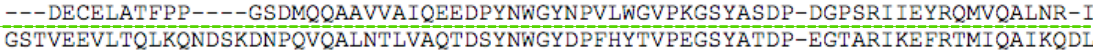
GSTVEEVLNQLKQSDSQDNPQVQALNTLVAQTDSYNWGYDPFHYTVPEGSYATDP-EGTTRI KEFRTMIOAIKODI PLDAYNWGYNPLHFFAPEGSYASNPHDPOTRKTELKOMINTLHQ-H -

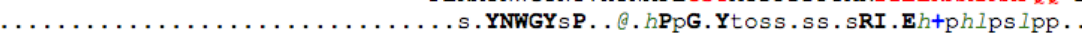
I $\stackrel{\mathrm{H} 404}{*}$ $5 8 6 \longdiv { 9 6 9 6 8 9 }$ M440 GCAILDVVYNHTAKV------DIFEDLEPNYYHFMDADGT -PRTSFGGGRLGTTHHMTKRLLVDS I KYLVDTYKV DMGVVLDVVFNHTAQV------HIFEDLVPNYYHFMDADGT - PRT SFGGGRLGTTHEMSRRVLVDSI KHWVDEYKV GMGVILDVVYNHTAKT-----YYLEDIEPNYYHFMNEDGS-PRESFGGGRLGTTHAMSRRVLVDSIKYLTSEFKV GMGVIFDVVYNHTART-----YYLEDLEPNYYHFMNADGT-ARESFGGGRLGTTHAMSRRI LVDSITYLTREFKV GMGVI LDVVYNHTSKT------FLFEDLEPNYYHFMEADGT-AKSSFGGGRLGTTHYMSRRVLVDS I KYLVDEFKV GLRVVMDVVYNHLYSSGPFAITSVLDKIVPGYYLRRSNGQ-TENSAAVNNTASEHEMVDRL IVDDLINWAVNYKV GLRVVLDVVYNHLNSSGPSDDNSVLDKIVPGYYLRRDNDGA-IENSTCVNDTASEHFMVERL ILDDLKHWAVNYKV GLRVVMDVVYNHLDSSGPCGISSVLDKIVPGYYVRRDTNGQ-IENSAAMNNTASEHFMVDRLIVDDLLNWAVNYKI GLNVVLDVVYNHLHASGPHDKESVLDKIVPGYYLRRNSDGE-IENSTCVNNTASEHYMVDRLIRDDLLNWVVNYKV GLRVVMDVVYNHLDSSGPFGVSSVLDKIVPGYYLRRNVNGQ- IENSAAMNNTASEHFMVDRLTVDDLLNWAINYKV GISVVMDMVLNHVYSQSA----SAFEKAEPGYYFRKN------TQSGCGNDTASNHEMFGKYI IDSVTYWAKNYDI HIGVNMDVVYNHTFATOI----SDFDKIVPEYYYRTMMOVI I PTDOVLEMKLXAERPMVQKE I IDSLKYWVNEYHI GIRVIMDVVYNHT FNTDE----SNFERTVPGYFYRQKEDKTLANGSGCGNETASERLMMRKEMVESVLYWIKEYHV HIGVNMDVVYNHT FATQI----SDFDKIVPEYYYRTDDAGNYTNGSGTGNE IAAERPMVQKE I I DSLKFWVNEYHV GLYVVMDVVYNHVYNASE----HAFNKTVPGYYFRYDANGNLTNGSGCGNDVASERAMARKY IVDSVKYWATEYNV GIGVVMDVVFNHTYHTKGG-KF SIFDKIVPEYFYRVDDYGDYSNATGCGNELATEKPMVRKE ILDT I IYWTEEFHI GIRVILDMVFPHTWGVGV---MSPFDOAVPYYFYRIDKTGAYLNESGCGNVIASERPMMRKY IVDTLKWWVTEYK GLRVVMDAVYNHVYDREQ----SPLEKLVPGYYFRYDAYGOPANGTGVGNDIASERRMARRWIVDSVVFWAKEYGI GLRVVMDAVYNHVYDREQ----SPLEKLVPGYYFRYDAYGQPANGTGVGNDIASERRMARRWIVDSVVFWAKEYGI GIRVI KDVVYNHTYTVGD----SPFDL IVPKY FYRTDDKGNYTNGSGCGNEIASERPMVRKE IVDSVKYWATEYKI GIRVIKDVVYNHTYTVGD----SPFDL IVPKY FYRTDDKGNYTNGSGCGNEIASERPMVRKF IVDSVKYWATEYKI GIRVIMDVVYNHVYIRDQ----SSFEKIVPGYYFRYDAYGNPSNGTGVGNDIASERKMVRKWI I DSVRFWVEEYHV GIRVI I DVVYNHVYEREL----SSFEKLVPGYYFRHGENGMPSNGTGVGNDIASERKMMRKE IVES I LYWLTEYNV NLRVVMDVVYNHMYNAAE----SNFHKLVPGYYYRYNEDGTFANGTGVGNDTASERKMMRKEMI DSVTYWAKEYNL NLRVVMDVVYNHMYSATE----SNFHKLVPGYYYRYNEDGTFANGTGVGNDTASERKMMRKFMI DSVTYWAKEYNI GIGVIMDMVF PHTYGIGE---LSAF DQTVPYY FYRIDKT GAY LNE SGCGNVIASERPMMRKF IVDTVTYWVKEYHI DIGVIMDMVEPHTYGIGE---LSAFDQTVPYYFYRIDKTGAYLNESGCGNVIASERPMMRKF IVDTVTYWVKEYHI GLRVVMDAVYNHVYDREO----SPLEKLVPGYYFRYDAYGOPANGTGVGNDIASERRMARRWIVDSVVFWAKEYGI GLRVVMDAVYNHVYDREQ----SPLEKLVPGYYFRYDAYGOPANGTGVGNDIASERRMARRWIVDSVVFWAKEYGI GMGVI LDVVYNHTAKT------YLFEDIEPNYYHFMNEDGS - PRESFGGGRLGTTHAMSRRVLVDS I KYLTSEFKV GMGAILDVVYNHTAKV------DLFEDLEPNYYHFMDADGT-PRTSFGGGRLGTTHHMTKRLLIDS I KYLVDTYKV GLRVVMDVVYNHLDSSGPCG ISSVLDKIVPGYYVRRDTNGQ-IENSAAMNNTASEHFMVDRL IVDDLLNWAVNYKV

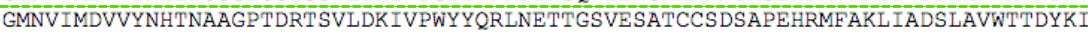
GMNVIMDVVYNHTNAAGPTDRTSVLDKIVPWYYQRLNETTGSVESATCCSDSAPEHRMFAKL IADSLAVWTTDYKI GLRVILDVVFNHVYKREN----SPFEKTVPGYFFRHDECGKPSNGTGVGNDIASERRMARKF IADCVVYWLEEYNV RIGVNMDVVYNHTFDVMV----SDFDKIVPQYYYRTDSNGNYTNGSGXGNEFATEHPMAQKFVLDSVNYWVNEYHV GIRVILDVVYNHVYVRET----SSFEHLVPGYYFRYERNGYPSNGTGVGNDLASERKMVKKEI IDSVTYWLKEYGV

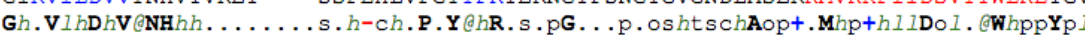
eeeeeee hhhhhhhhhhhhhhhh

(Figure is continued on the following pages) 


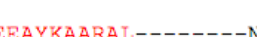
gi 20954107 DGFRDMMGHDAAAIELAYKEAKAI gi_209541307_gb_ACI61883. DGFRFDMMGDHDAAAIEQAFKAAKAI-

6 (1) gi $3411266 \mathrm{~g} \overline{\mathrm{b}}$ AAD 11599.1

GH13_13 gi_23330127 gb_AAN26412.1 gi_119633045 g $\bar{b}$ ABL 84490 . gi-27311611_gb_ēAO00771.1 gi_161085685 dbj_BAF93906 gi_5969549_gb_AAĒ10887.1.

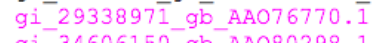
gi_34606150_gb_AAQ80298.1 gi $666867 \mathrm{gb}$ ĀABO 6264.1 gi_4836215_gb_AAD30387. gi_56381204_dbj_BAD77112. gi_23476935_emb_CAC85704. gi_44662948_gb_ĀAS47565.1 gi-37788269_gb_AAP45012.1 ---NPNI IMLGEGWRTETGDANQPVQPAD--QDWMSSTDTVAVFS DGFREDLMGH IMKHTMMRAKAALQS LTRDAHGVDGSKIYLYGEGWDFAEVARNQRGINGS--QLN-MSGTGIGSFN DGFRE DLMGH IMKATIVNAKSAIGS LRKET DGVDGSRIYL YGEGWNFGEVAENGRGINAS--QFN-LGGTGIGSFN DGFREDLMGH IMKSTMIRAKSAIRS LTRDVHGVYGSKIYLYGEGWDFGEVAQNKRGINAS--QIN-MSGTGIGSFN DGFREDEMTLIDSTTMNKLRAALTAL-------DPHI IMYGEGWGDSNANNI---PETS-INNY-KNVPGIGFFN DGFREDLMALLGKDTMSKAASELHAI--------NPGIALYGEPWTGGTSALP---DDQLLTKGA-QKGMGVAVFN DGFRF DLMGIHDIETMNE IRKAVNAV-------DPTICI YGEGWAAEAPOY P--ADSLAMKGNI-AOI PGVAVES DGFREDLMALLGKDTMSKAATQLHAI--------DPGIAL YGEPWTGGTSALP---ADQLLTKGA-QKGMGVAVFN DGFREDLMGL IDQTTMNQVRAALDEI--------DPS ILVIGEGWDMTDAIGN---QETT-QPNA-SKVKGVAFFN DGFREDLMGLLTVKQSRQVANEVRKR--------NPKALVYGEGWVMGNSTCL-VEEMATILSSC-HQGYSIGLFN DGFREDQMGLMDKVTMLAIKSELSKI--------EPSVVLYGEPWGGWGAPIR---FGKAD-----VGGTGIAAFN DGFREDLMGVHDIETMKAVRDALDAI--------DPS ILVYGEGWDLPTPLPP--EOKAT--MANAKQLPRFAYFN DGFRFDLMGVHDIETMKAVRDALDAI--------DPS ILVYGEGWDLPTPLPP--EQKAT--MANAKQLPRFAYFN DGFRFDLMALHDVETMLAVQEALHQI--------DPSIIIYGEPWQAGGSPLP---ANLQETKGK-QRGTRIAVFN DGFREDLMALHDVDTMLEVQQALHQI--------DPS I I Y YGEPWQAGGSPLP---ANLQETKGK-QRGTKIAVFN NGFRFDLMGI LDVETMKAVREMLDTL-------DPS ILVFGEGWDLPTPLSS--EQKAT--MQNAEKLPRIGYFN DGFREDLMGI LDVDT INI IEKEVRNI-------KRDALLLGEGWDLQTPLPL--EEKAT--LNNAKKMPHIAQEN DGFREDLMGI HDYETMNEIRKAVNOI-------DPS I I LHGEGWDLNTPLAA--ELKAN--OKNAEKMKGIAHFN DGEREDLMGIHDYETMNE IRKAVNQI-------DPS I I LHGEGWDLNTPLAA--ELKAN--QKNAKKMKGIAHFN DGEREDQMGLIDKKTMLEVERALHKI--------DPTI I L YGEPWGGWGAPIR---FGKSD-----VAGTHVAAFN DGFRFGQMGLIDKKTMLEVEKALHKI--------DPTI I YYGEPWGGWGAPIR---FGKND-----VAGTHVAAFN DGFREDLMGVHDIETMKAVRDALDAI-------DPS ILVYGEGWDLPTPLPP--EQKAT--MANAKQLPRFAYFN DGEREDLMGVHDIETMKAVRDALDAI-------DPS I LVYGEGWDLPTPLPP--EQKAT--MANAKQLPRFAYFN DGFREDMMGDHDAAAIELAYKEAKAI--------NPNMIMIGEGWRTFQGDQGKPVKPAD--QDWMKSTDTVGVFS DGERF DMMGDHDAAS IEEAYKAARAL-------NPNLIMLGEGWRTYAGDENMPTKAAD--QDWMKHTDTVAVFS

GH13_12

GH13_13

GH13_14 gi- 401063635 gb gi $401063637 \mathrm{gb}$ AFP89963. gi_4982428_ḡ gi_224579361_ōgb_ACN58254. gi_3089609_gb_AĀC15073.1

gi $14861067 \mathrm{dbj}$ BAB62095.

3faw_chainA_p001

2 yao chainA p002

4 aio chainA p003

2fgz_chainA_po 4

2yoc_chaina_p005

2e8y_chainA_p006

2wan_chainA_p007

3wdh_chainA_p008

Consensus aa:

Conservation:

Con AAG33958.1 DD 11320925 gb

GH13_12

gi 42712988 gb_AAS36537.1 DEFRNELKSGEGS--EGQPREITGGAV-N

gi_209541307_gb_ACI61883. DDIRNTLKSGEPN--EGTAAFITGGAK-N-

gi 251820781 emb CAR47543 DEIRNTLKSGYPN--EGQPAFITGGAK-S-

gi $3411266 \mathrm{~g} \overline{\mathrm{b}}$ AAD 11599.1

GH13_13

gi_2333012 $\overline{7}$ g $\bar{b}$ _AAN2 $6412 . \overline{1}$ gi_119633045_gb_ABL84490.

DIRDATNCC

DRIRDAVLGGG

DRIRDAVNGGN NPNLIMLGEGWRTYAGDENMPTKAAD--QDWMKHTDTVAVFS
GSKIYLYGEGWDFAEVARNORGINGS--QLN-MSGTGIGSFN DGFREDLMGH IMKRTMMRAKSALQS LTTDAHGVDGSKIY IYGEGWDFAEVARNQRGINGS--QLN-MSGTGIGSFN DGFREDLMGYHPKAQILSAWERIKAL--------NPDIYFFGEGWDSNQSDRE---EIAS--QIN-LKGTGIGTFS 作 D. DGFREDLMGILDI DTMNDVRRAIDEI--------DPTVI I LGEGWDLATPLPS--EKKTT--IANAKHTPRIAYFN

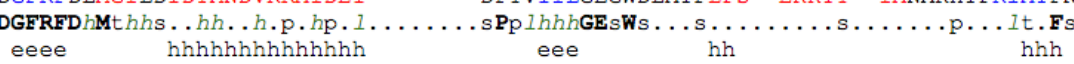

hh

hhh

3172048 dbj-BAA28632.1

gi $1610856 \overline{8} 5 \mathrm{dbj}$ BAF93906

gi $5969549 \mathrm{~g} \overline{\mathrm{b}}$ AAE 10887.1

gi_29338971_gb_AA076770. gi_34606150_gb_AAQ80298.1 gi 68271034 gb AAY89038. gi $666867 \mathrm{gb}$ AAB06264.

gi $483621 \overline{5} \mathrm{gb}$ AAD30387. gi_56381204_dbj_BAD77112. gi_23476935_emb_CAC85704. DRIRDATLGGS PGERDAISNN DNLRNALDGN DELRDGLCGP DNLRNGLDG DSLRDAIKG DRIRDAIRG DEFRDALRGS DRERDAVKGS DRERDAVKGS DHIRNAIKGD DHIRNAIKGD gi_37788269_gb AAP45012. gi_228654_prf_1808262A gi $401063 \overline{635} \overline{\mathrm{gb}}$ AFP89962. gi_401063639_gb_AEP89964. gi_401063637_gb_AFP89963. gi_4982428_gb_AĀD36907.1 gi_224579361_gb_ACN58254. gi_3089609_gb_AAC15073.1

GH13_12

DYFRDSVKG

DNIRDGLKGS

DNIRDGLKGS

DEFRDAIRGS

DEFRDAIRGS

DRFRDAVKGS

DRERDAVKG

DDIRNSLKSG

GNPLQQGFSTGL-----FLEPNGFYOGNETETRLTLATYADHIOIGIAGNLKDYVVISHTGEA F GP PLQQGYVTGL-----SLQPNDHDHSGKANADRMLAVAKDH IQVGMAGNLRDY I LTNCDGKQ FE GNPLQQGFNTGL-----FLEPNGFYQGNEADTRRSLATYADQIQIGLAGNLRDYVLITHTGET GHPLQQGEITGL-----LLQPNAHDHGSEATQELMLSTAKNHIQTGMAANLKDYMLTNHEGKE ENPLOQGESTGL-----FLEPNGYYOGNEADTRRELATYADHIOIGLAGNLKDYVLRTHTGEA --SAGGFAAGNTA-STTTVAG--

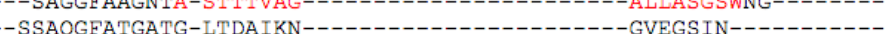

-KRKGAFLAGIPG-GEMSVKF-------------------GIAGAIEHPQVQCDSVNY SSAOGEATG -DEDTGFIAGKAD-KENLIAT-_-_-_-_-_-_-_-_-_-_--NVLGCNNKREGIDENGHC -YKTGYVHGNLS-DVGRLKO--

-ATVKGELMGALA-KETGVKR--1

-

-IPDRGFAIGNPG-GRE LPDGEALGNPG-GREQVKL TIKGTVQMVN-QRDNVIR

AIAGSLRALG------GIMGAID-

-LPDRGFALGDSD-DREKVKV-------------------AISGS IGKKN-

L

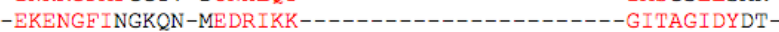

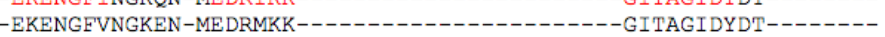

-PSVKGFVMGGYG-KETKIKR--------0---0----GVVGSINYDG

-PSVKGEAMGGYG-KETKIKR------------------GVVGSINYDG-------

-LPDRGFALGNPG-GREQVKL--

-LPDRGFALGNPG-GREQVKL

AIAGSLRALGDRIRDAINGGNPFGNPLQQGENTGL---FLEPNGFYQGNEADTRRSLATYADQIQIGLAGNLRDYVLISHTGEA DRLRDAVRG GPF DSGDALRQNQGVGGAGVPNELTT-DISDDQARHLADLTRLGMAGLADFVLIDKDGAV DRLRDSVRGG GPF-DSGDALRQNQGIGSGAGVLPNELAS----LSDDQVRHLADLTRLGMAGNLADFVMIDKDGAA

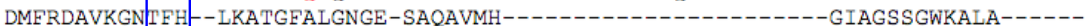
DNIRNGLDGN VFD--KTAQGFATGDPN-QVDVIKN------

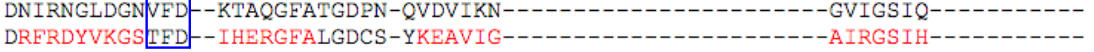

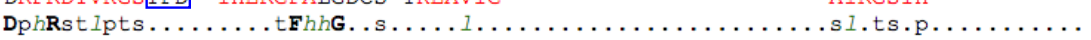
hhhhhhhhh hhhhhhh hhhhhh hhh hh 
$\underset{*}{\mathrm{~F} 620} \quad$ IV $^{\mathrm{D} 642}$

Conservation :

$\begin{array}{lllllll}8 & 5 & 6 & 96 & 996 & 86 & 9\end{array}$

75

7689568

gi 11320925 gb AAG33958.1 gi_42712988_gb_AAS36537.1 gi $77173560 \mathrm{gb}$ EA076676.1 gi $20954130 \overline{7} \mathrm{gb}$ ACI 61883 . gi_251820781_emb_CAR47543 gi_3411266_gb_AADי11599.1 gi_23330127_gb_AAN2 6412.1

GH13_13 gi $11963304 \overline{5}$ gb ABL84490. gi_27311611_gb_ĀAO00771.1 gi_3172048_dbj_BAA28632.1 gi_161085685_dbj_BAF93906 gi $5969549 \mathrm{gb}$ AAE10887.1 gi $2933897 \overline{1}$ gb AA076770. gi $34606150 \mathrm{gb}$ AAQ80298. gi $68271034 \mathrm{gb}$ AAY89038.

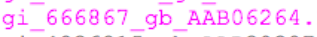
gi_483621 $\overline{5}$ gb $\bar{b}$ _AAD30387. gi_56381204_dbj_BAD77112. gi 23476935emb_CAC85704.

GH13_14 gi 44662948 gb ĀAS47565. gi 37788269 gb AAP45012. gi_228654_prf_1808262A gi_401063635_gb_AFP8996 gi_401063639_gb_AFP89964. gi $401063637 \mathrm{gb}$ AFP89963. gi $4982428 \mathrm{~g} \bar{b}$ A.ADD36907.1 gi_224579361_gb_ACN58254.

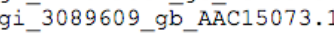
gi $1486106 \overline{7} \mathrm{db} j$ BAB 62095.

GH13_12 3 faw_chainA_p001 2yao chainA p002 4 aio chainA p003 2fgz_chainA_p004 2yoc chainA_p005 2e8y_chainA_p006 2wan chainA p007 3wdh chainA p008 Consensus aa: Consensus ss:

-TNFEADSPGDVIQYIAAHDNLTLFDIIAQS IKKDPSKAENYAEIHRRLRLGNLMVLTAQGTPFI HNMADOPGDVVOY IEAHDNLTLYDVIAOS IKKDPEIAENDLEIHKRIRVGNAMVLTSOGTAFI GNFEADSPGDVVOYIAAHDNLTLHDVIAKS INKDPKVAEE--DIHRRLRLGNVMILTSOGTAFI -SNFEADAPGDVVQYIAAHDNLTLHDVIAKS INKDPKVAEE--EIHKRIRLGNTMILTAQGTAFI -GNE LADDPGDVIQYIAAHDNLTLFDI IAQS IKKDPSVTENYTEIHQRQRLGNLLVLTAQGTPFI RKGSEIRTFDGSPVGYASSPIETINYASAHDNETLFDI ISLKTPMD----LS IDERCRINHLST SMIALSQGIPFF VKGSEVYTYGGTPVGYAMQPIETINYVSAHDNETLFDIVSLKTPTY----ITVDERCRVNHLATS ILALSQGIPFF KKGSEIHTFDGL PVGYTSSPIEI INYVSAHDNETLFDVISVKTPMN----LSVDERCRINHLASSMMALSOGI PFE VKGSEVLMHDATPVAYASLPTETINYVSAHDNETLFDI ISLKTPME-----ISVDERCRINHLASSMIALSQGIPFF KKGSDIYTFDGSPVGYTSSPVETINYVSAHDNETLFDIVSIKTPIG----LS IDEKCRINHLASSMIALSQGIPFF -------NGTVQAFLTPSQS INYVECHDSFTLNDS LWSADPN-----DSVATHQARVTLANATN ILANGVTFM

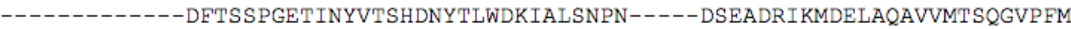
TOKPWAKQPVQMISYVSCHDGLCLVDRLKASMPD-----ITPEQLIRLDKLAOTVVETSQGI PFI -DFTASPGETINYVTSHDNYTLWDKIAOSNPN-----DSFADRIKMDELAOAIVMT SOGI PFM NNG------TADTNYGGADOVVOYVE IHDNLTLYDKLVKSAPN-----DSEETRLARAKLADSLILISOGIADM NNG------TADTNYGGADQVVQYVE IHDNLTLY DKLVKSAPN-----DSEETRLARAKLADS IILISQGIADM -------EVIRS FAKDPQETINYVEVHDNHTLWDKNYLAAQADTTVKWTEEMLKDAQKLAGAILLTSQGIPFL ---GLFCHPRQS INYVECHDNHTFWDKMEAANHD-----EPEWLRRKRQKLATAIVLLAQGI PFL -GLFCHPRQS INYVECHDNHTFWDKMEAANHD-----EPEWLRRKRQKLATAIVLLAQGIPFL -DFAOEPTESIVYVSCHDNLTLWDKIEKSNPN-----DSEEDRTRMNLLANATVLTSOGVPET -DFAOEPTES IVYVTCHDNLTLWDKIEKSNPN-----DSEEDRIRMNLLSNAIVLTSQGVPFL -GLFLHPTQTINYVESHDNHTFWDKME IANGH-----ESEQTRKKRQKLATAIVLLSQGIPFL -ETGLFLEPVQS INYVECHDNMTMWDKLMRSNEE------SEEILKKRHLLATAMVILSQGIPFL -NSSTYQDPEQVLTYVEAHDNHTLWDKLELTNSG----DNEEVRKQMHKLSSS ILLTSQGIPFL -NSSTYQDPEQVLTYVEAHDNHTLWDKLELTNPS-----DSEEVRKQMHKLSSS ILLTSQGIPFL

KLIKSFALDPEETINYAACHDNHTLWDKNYLAAKADKKKEWTEEELKNAOKLAGAILLTSOGVPFI

KLIKSFASDPEETINYVACHDNHTLWDKNYLAAKADKRKKWTEEELKNAQKLSGAIILTSQGVAFL GLFCHPRQS INYVECHDNHTFWDKMEAANHD-----EPEWLRRKRQKLATAIVLLAQGIPFL -GLFCHPRQS INYVECHDNHTEWDKMEAANHD-----EPEWLRRKRQKLATAIVLLAQGIPFL

-GNFEADSPGDVVQYIAAHDNLTLHDVIAKS INKDPKVAEE--DIHRRLRLGNVMILTSQGTAFI -TNEEADSPGDVIOYIAAHDNLTLFDIIAOSIKKDPSKAENYAEIHRRLRLGNLMVLTAOGTPFI KKGSE IHT FDGLPVGYTASPIETINYVSAHDNETLFDVISVKTPMI-----LSVDERCRINHLAS SMMALSQGIPFF KRGSEIDY-NGAPGGYAADPTEVVNYVSKDNQTLWDMISYKAAQE---ADLDTRVRMQAVSLATVMLGGIAFD KKGSEIDY-NGAPGGYAADPTEVVNYVSKHDNQTLWDMISYKASQE----ADLATRVRMQAVSLATVMLGQGIAFD $----------P I V P E P S Q S I N Y V E S H D N H T$ FWDKMSFALPQ-----ENDSRKRSRQRLAVAI I LLAQGVPFI -----------DETSAPSETINYVTSHDNMTLWDKILASNPS-----DTEADRI KMDELAHAVVET SQGVPFM

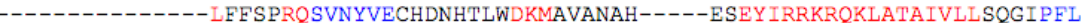

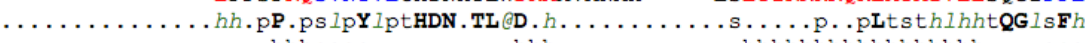

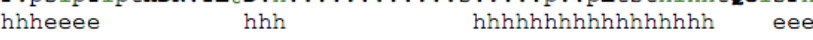

Conservation:

$\begin{array}{llll}5 & 9 & 8 & 869\end{array}$

$\begin{array}{lllll}668 & 6 & 6 & 8 & 55\end{array}$

GH13_12

(6) gi $42712988 \mathrm{gb}$ AAS 36537.1 HAGQEFGRTKQWRAPATEAPYKST-------YMTDADGNPFVYPYFIHDSYDSSDIINRFDWEKATDA--------gi_77173560_gb_EA076676.1 HSGQEYGRTKRLLNPDYMTKVSDDK----LPNKATLIEAVKEYPYFIHDSYDSSDAINHFDWAAATDN--------gi_209541307_gb_ACI61883. HSGQEYGRTKQLLNPDYKTKVSDDK----VPNKATLIDAVAQYPYFIHDSYDSSDAVNHFDWAKATDS--------gi_251820781_emb_CAR47543 HSGQEYGRTKQFRHPDYKEPVTEDKVPNKAHLLTNADGTPFDYPYYIHDSYDSSDAVNKFDWTKATDE---------

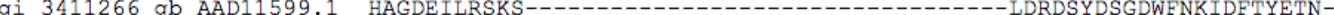
1

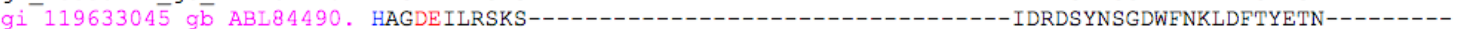

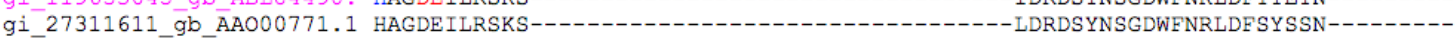
gi $3172048 \mathrm{dbj}$ BAA28632.1 HAGDEILRSKS-----------------------------LDRDSYNSGDWFNKLDFTYETN---------

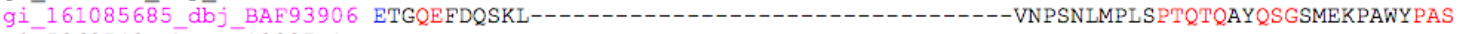
gi $5969549 \mathrm{gb}$ AAE10887.1 QGGEEMLRXKG-----------------------------GNDNSYNAGDAVNEFDWSRKAQ-------(1-5969549 g gi 34606150 gb AAQ80298.1 gi_ 68271034 gb AAY89038.1 gi_666867_gb_ĀABB06264.

Q

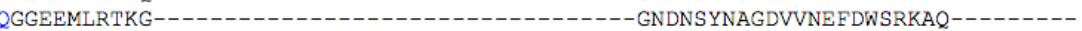

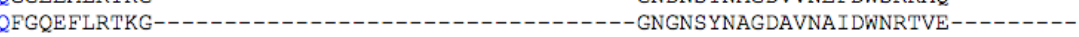
HGGVEFNRSKG----------------------------GHPNTYNAGDNINKIDWSLKEK--------

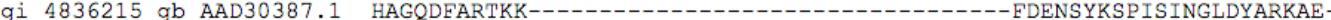

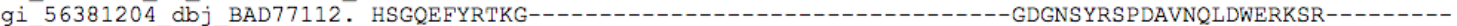
gi 23476935 emb CAC85704. HSGQE

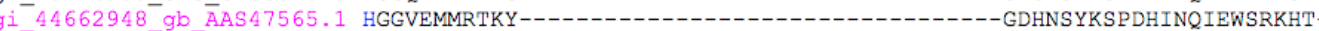
i 37788269 gb AAP45012.1 HGGVEMMRY

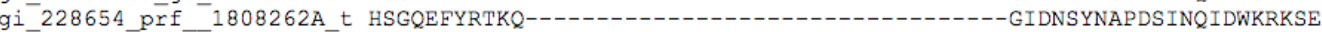
gi $401063635 \mathrm{gb}$ AFP 8962 . HAGQEFYRTKQ-------------------------GNENSYNANDEINQLDWDRKEK

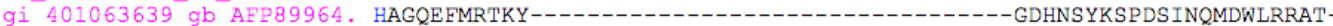
gi 401063637 gb AFP89963. gi 4982428 g $\bar{b}$ A A A D 36907.1 gi 224579361 gb ACN58254. gi $3089609 \mathrm{~g} \bar{b}$ A $\bar{A} C 15073.1$

GH13_12 3 2 yao chainA_p002 4aio chainA p003 2 yoc chainA p005 $2 \mathrm{e} 8 \mathrm{y}$ chainA p006 2wan chainA p007 wan_chainA_poo Consensus aa: Consensus ss:

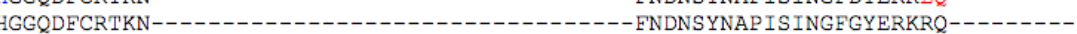

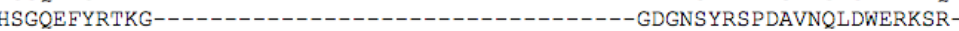

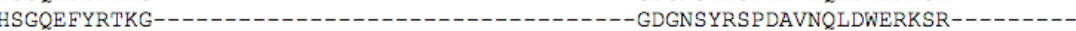
HSGQEYGRTKRLLNPDYMTKVSDDK---- LPNKATLIEAVKEYPYFI HDSYDSSDAINHFDWAAATDN--------

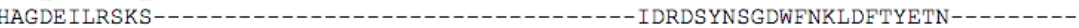
QQ

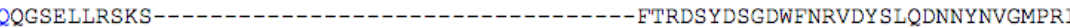

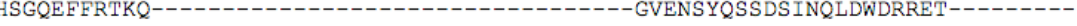

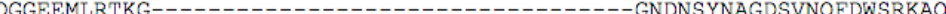

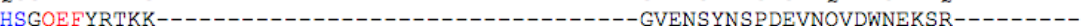

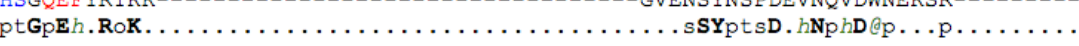

(Figure is continued on the following pages) 


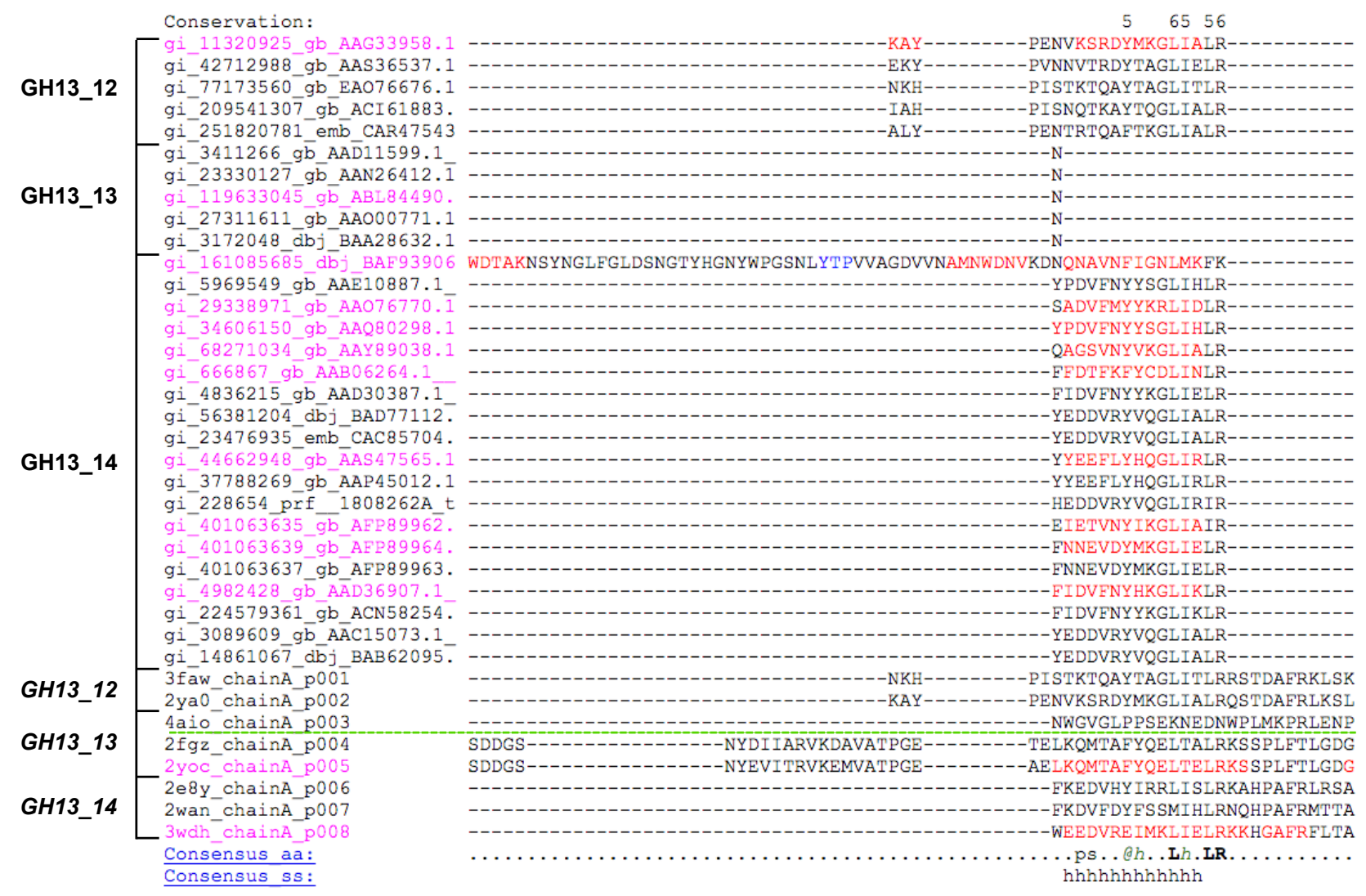

Figure S7. Structure guided multiple sequence alignment of the catalytic domains of GH13_12-14 limit dextrinases and pullulanases, which are classified as characterized in the CAZy database. The sequence of $H \nu \mathrm{LD}$ (PDB entry 4AIO) is underlined in green. The conserved amino acid motifs [1] of GH13 are labeled, and the amino acid resides discussed in the paper is indicated by an asterisk (residues numbered according to $H \nu \mathrm{LD}$ ). The region around Phe553 of $H \nu \mathrm{LD}$ is marked by a blue box. The range of the catalytic domains (superfamily c107893; AmyA_Pullulanase_LD-like) were chosen based on information from Conserved Domain Database [2, 3].

The structure guided multiple alignment was generated using PROMALS3D [4]. The sequences are colored according to secondary structure (red: $\alpha$-helix, blue: $\beta$-strand). The consensus secondary structures are indicated below the alignment by $\mathrm{h}$ ( $\alpha$-helix) or e ( $\beta$-strand), furthermore the consensus amino acids are shown by the following symbols: conserved residues, bold and uppercase letters; aliphatic residues, $l$; aromatic residues, @; hydrophobic residues, $h$; polar residues, p; tiny residues, t; small residues, s; bulky residues, b; positively charged residues, + ; and negatively charged residues, - . 


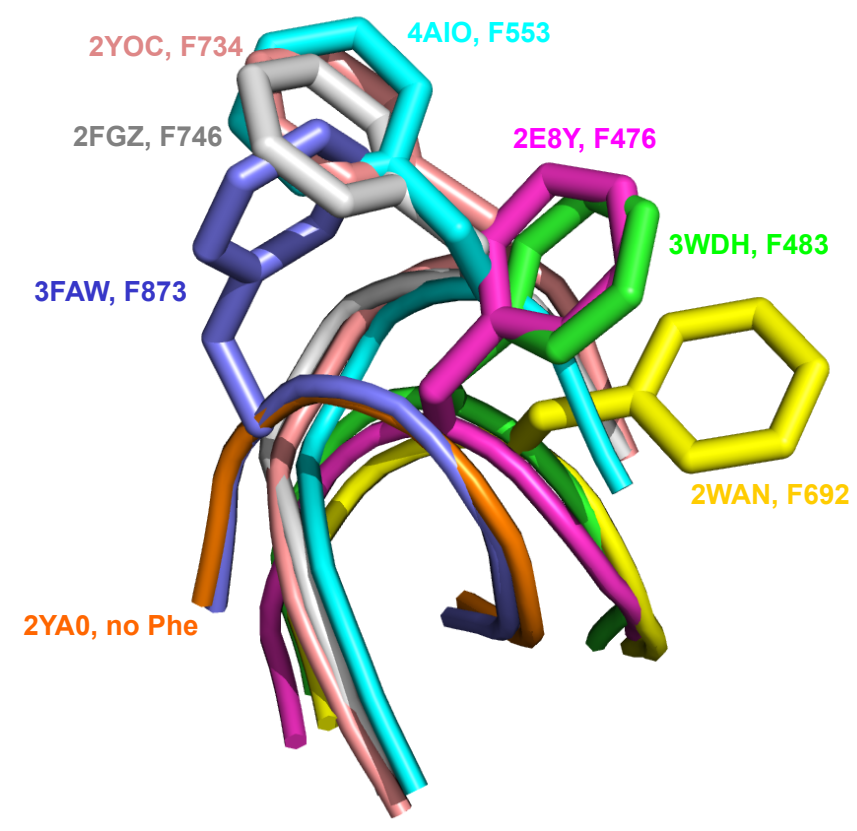

Figure S8. Superimposition of the crystal structures from GH13_12-14 with focus on the residues equivalent to Phe553 of $H v \mathrm{LD}$ (PDB entry 4AIO). 


\section{Supplemental Video}

Video of subsites and secondary interactions site details outside the active site cleft of $H v \mathrm{LD}$ as described in Figure 3 in the manuscript.

\section{Supplemental References}

[1] MacGregor EA, Janecek S, Svensson B. Relationship of sequence and structure to specificity in the $\alpha$ amylase family of enzymes. Biochim. Biophys. Acta, Protein Struct Mol Enzymol 2001;1546;1-20.

[2] Marchler-Bauer A, Anderson JB, Chitsaz F, Derbyshire MK, DeWeese-Scott C, Fong JH, Geer LY, Geer RC, Gonzales NR, Gwadz M, He S, Hurwitz DI, Jackson JD, Ke Z, Lanczycki CJ, Liebert CA, Liu C, Lu F, Lu S, Marchler GH, Mullokandov M, Song JS, Tasneem A, Thanki N, Yamashita RA, Zhang D, Zhang N, Bryant SH. CDD: specific functional annotation with the Conserved Domain Database. Nucleic Acids Res 2009;37;D205-D210.

[3] Marchler-Bauer A, Zheng C, Chitsaz F, Derbyshire MK, Geer LY, Geer RC, Gonzales NR, Gwadz M, Hurwitz DI, Lanczycki CJ, Lu F, Lu S, Marchler GH, Song JS, Thanki N, Yamashita RA, Zhang D, Bryant SH. CDD: conserved domains and protein three-dimensional structure. Nucleic Acids Res 2013;41;D348-D352.

[4] Pei J, Tang M, Grishin, NV. PROMALS3D web server for accurate multiple protein sequence and structure alignments. Nucleic Acids Res 2008;36;W30-W34. 